Article

\title{
Entropies and Scaling Exponents of Street and Fracture Networks
}

\author{
Nahid Mohajeri ${ }^{1}$ and Agust Gudmundsson ${ }^{2, *}$
}

1 UCL Department of Geography, University College London, 1-19 Torrington Place, Gower Street, London WC1E 7HB, UK; E-Mail: nahid.mohajeri.09@ucl.ac.uk

2 Department of Earth Sciences, Queen's Building, Royal Holloway University of London, Egham TW20 0EX, UK

* Author to whom correspondence should be addressed; E-Mail: a.gudmundsson@es.rhul.ac.uk.

Received: 23 March 2012; in revised form: 7 April 2012 / Accepted: 10 April 2012 /

Published: 19 April 2012

Abstract: Many natural and man-made lineaments form networks that can be analysed through entropy and energy considerations. Here we report the results of a detailed study of the variations in trends and lengths of 1554 named streets and 6004 street segments, forming a part of the evolving street network of the city of Dundee in East Scotland. Based on changes in the scaling exponents (ranging from 0.24 to 3.89 ), the streets can be divided into 21 populations. For comparison, we analysed 221 active crustal fractures in Iceland that (a) are of similar lengths as the streets of Dundee; (b) are composed of segments; and (c) form evolving networks. The streets and fractures follow power-law size distributions (validated through various statistical tests) that can be partly explained in terms of the energies needed for their formation. The entropies of the 21 street populations and 9 fracture populations show strong linear correlations with (1) the scaling exponents $\left(\mathrm{R}^{2}=0.845-0.947\right.$ for streets, $\mathrm{R}^{2}=0.859$ for fractures $)$ and with $(2)$ the length ranges, that is, the differences between the longest and shortest streets/fractures, $\left(\mathrm{R}^{2}=0.845-0.906\right.$ for streets, $\mathrm{R}^{2}=0.927$ for fractures).

Keywords: street networks; fracture networks; power laws; scaling exponents; entropy

PACS Codes: 00, 05, 80, 90, 91 


\section{Introduction}

Power-law distributions are very common in artificial (man-made) and natural phenomena [1-4]. Power laws are scale free (scale invariant); in contrast to, say, normal (Gaussian) distributions, there are no objects (or events or processes) that are typical for the distribution as a whole [3]. Following early pioneering studies $[5,6]$ interest in and research on power laws have increased much during the last decades, with a large number of papers and many books being published on the topic [1,6-10].

The lengths of streets in a city and the lengths of crustal (rock) fractures analysed in this paper both follow power-law distributions. A street length is either the length from one junction to another, in which case we use the term 'street segment' or the entire length of street with a given name, in which case we use the term 'named street'. A rock (crustal) fracture is any mechanical break or discontinuity that separates a rock body (or a crustal segment) into two or more parts. One of many connections between streets and fractures is that the networks of streets in many cities are partly controlled by the shapes of the cities which, in turn, commonly depend on some landscape features. These features include valleys, rivers, mountain fronts, and the sea (the coast), many of which originate along crustal weaknesses, primarily crustal fractures [11-13].

One theme of this paper is that for many cities, particularly those whose shapes are largely controlled by landscape constraints, we may expect certain similarities between the development of the street networks and fracture networks in nature. We explore this theme with new data on street and fracture networks, in particular their trends (orientation) and length distributions. Although street networks have been studied before using different methods [14-18], not much quantitative data exist on the variation in street trends and lengths within cities. We are also unaware of any study that correlates street networks with city shape as controlled by external landscape factors. Similarly, while rock-fracture networks have been studied in many parts of the Earth's surface, we are unaware of any attempts to compare these with street networks in cities. A street/fracture network is a system of lineaments, some of which are interconnected. If the system is evolving (active), it exchanges energy (and sometimes matter) with its environment and is thus either a closed or, more generally, an open system. A street/fracture network seeks equilibrium with its surroundings, and may approach it during certain periods. In particular, the network may be in thermal equilibrium but then energy is exchanged to maintain the same temperature inside and outside the system. An evolving lineament network, however, receives energy input and, while expanding, does not reach equilibrium with its surroundings.

Here we explore the similarities (and dissimilarities) between two complex dynamic systems of lineaments, namely the street networks in a medium-size city and the fracture networks in a part of an active rift zone. We point out that streets and fractures have many geometric properties in common, such as that they are composed of segments, have similar length ranges, and follow power-law size distributions. Furthermore, both streets and fractures form parts of networks that evolve through time and need energy input for their growth. Thus, for a fracture/street of a given type, there is certain energy needed for a unit extension of a tectonic fracture, but also for a unit extension (construction) of a street. The main focus is on the street networks in the city of Dundee, an old city in East Scotland $[19,20]$, and the fracture networks in the Holocene (less than 10,000 year-old) basaltic lava flows of the rift zone in Southwest Iceland (Figure 1). Both types of networks occur within elongated (roughly 
elliptical or semi-elliptical) structures. The city of Dundee has a crude semi-elliptical boundary, part of which is determined by the coastline (a landscape boundary). Similarly, the fractures in Southwest Iceland are confined to fracture/fissure swarms which are roughly elliptical in shape, with the long axes coinciding with the axis of the rift zone itself.

The first aim of this paper is to quantify the trends (orientations) of streets in the city of Dundee, Scotland, and compare them with trends of fractures in the Holocene rift zone of Southwest Iceland. The second aim is to present and discuss the physical meanings of the scaling exponents and the calculated entropies of the power-law length distributions of streets and fractures. The third aim is to compare the entropies of the length-frequency distributions of the street and fracture populations with their scaling exponents, length ranges, and possible energy inputs in order to understand better their development.

Figure 1. (a) Location and overview of the city of Dundee, East Scotland. The city has an overall shape crudely similar to that of half an ellipse, where the major axis coincides with the northern coastline of the Firth of Tay. From Google Earth, the longitude and latitude of the city are also given. (b) Location and geometries of the fissure swarms of Southwest Iceland. All the fracture data used in the paper is from the networks or swarms marked A (Thingvellir) and B (Vogar). Also indicated is the direction of regional tension (large arrows) in this part of Iceland and the local tension across the fissure swarms (small arrows). The tensile stresses associated with these directions are the driving forces of fracture formation.
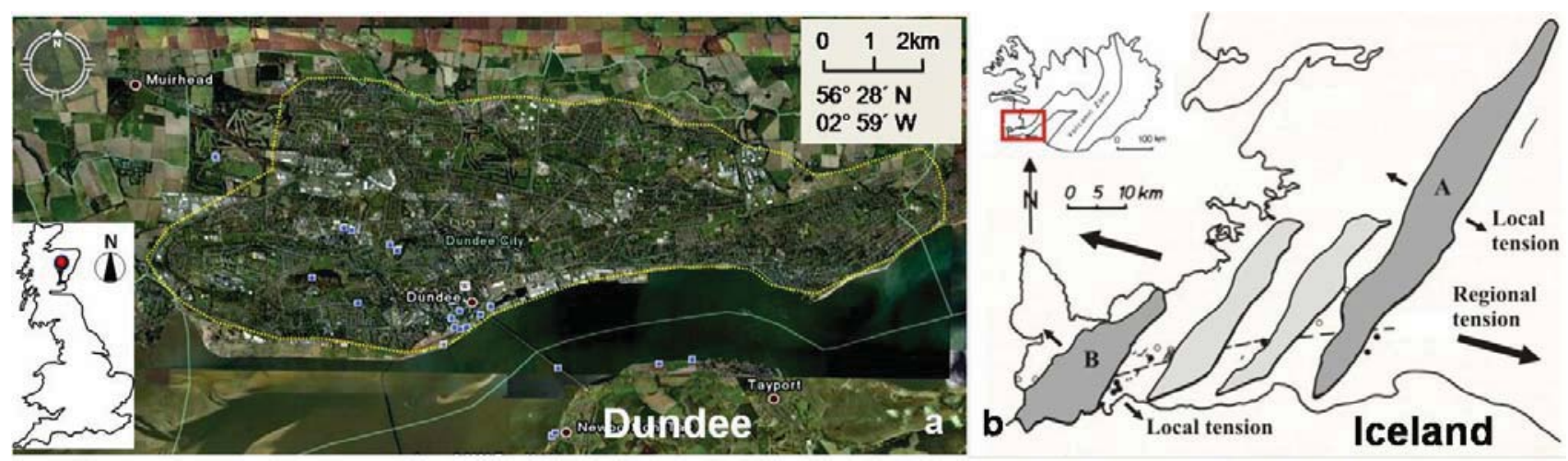

\section{Power Laws}

A frequency (probability) distribution, an equation in the form:

$$
p(x)=C x^{-D}
$$

is a power-law distribution where $\mathrm{p}(\mathrm{x})$ is the number or frequency of objects (here, the number of streets or fractures in a binned histogram), $\mathrm{C}$ is a constant of proportionality, and $\mathrm{D}$ is the scaling exponent [21]. In this paper, the power laws were normally fitted using programs such as Matlab [22] or Statistica [23].

To determine whether a distribution such as that shown in Figure 2 is really a power law, we plot the logarithms of the values $(x)$ and their probability $p(x)$, that is, $\log (p(x))=\log (C)-D \log (x) . A$ 
straight line on the log-log (bi-logarithmic) plot is then an indication that it is a power law (Figure 2). Further tests of power-law fits are in Section 8 and in [9].

For power laws based on histograms with certain bin widths or class limits the scaling exponent depends on the chosen class limits (their widths). Also, there is commonly a considerable noise at the lower end of the straight line because there each class has few, sometimes no, samples or observations so that there are large fluctuations in the counts (Figure 2). We therefore use cumulative frequency distributions and plot the cumulative probability $\mathrm{p}(\mathrm{x})$ that $\mathrm{x}$ has a value greater than or equal to $\mathrm{x}$, namely:

$$
p(x)=\int_{x}^{\infty} p\left(x^{\prime}\right) d x^{\prime}
$$

If the cumulative distribution follows a power law $p(x)=C x^{-D}$, then:

$$
p(x)=C \int_{x}^{\infty} x^{\prime-D} d x^{\prime}=\frac{C}{D-1} x^{-(D-1)}
$$

Figure 2. (a) Plot of all the 221 fractures measured in the fissure swarms of Thingvellir and Vogar using the class (bin) width of $200 \mathrm{~m}$. (b) A bi-logarithmic (log-log) plot, using Matlab, of the same fracture data $\left(\mathrm{N}\right.$ is number of fractures, $\mathrm{R}^{2}$ is the coefficient of determination, and $\mathrm{D}$ is the scaling exponent).

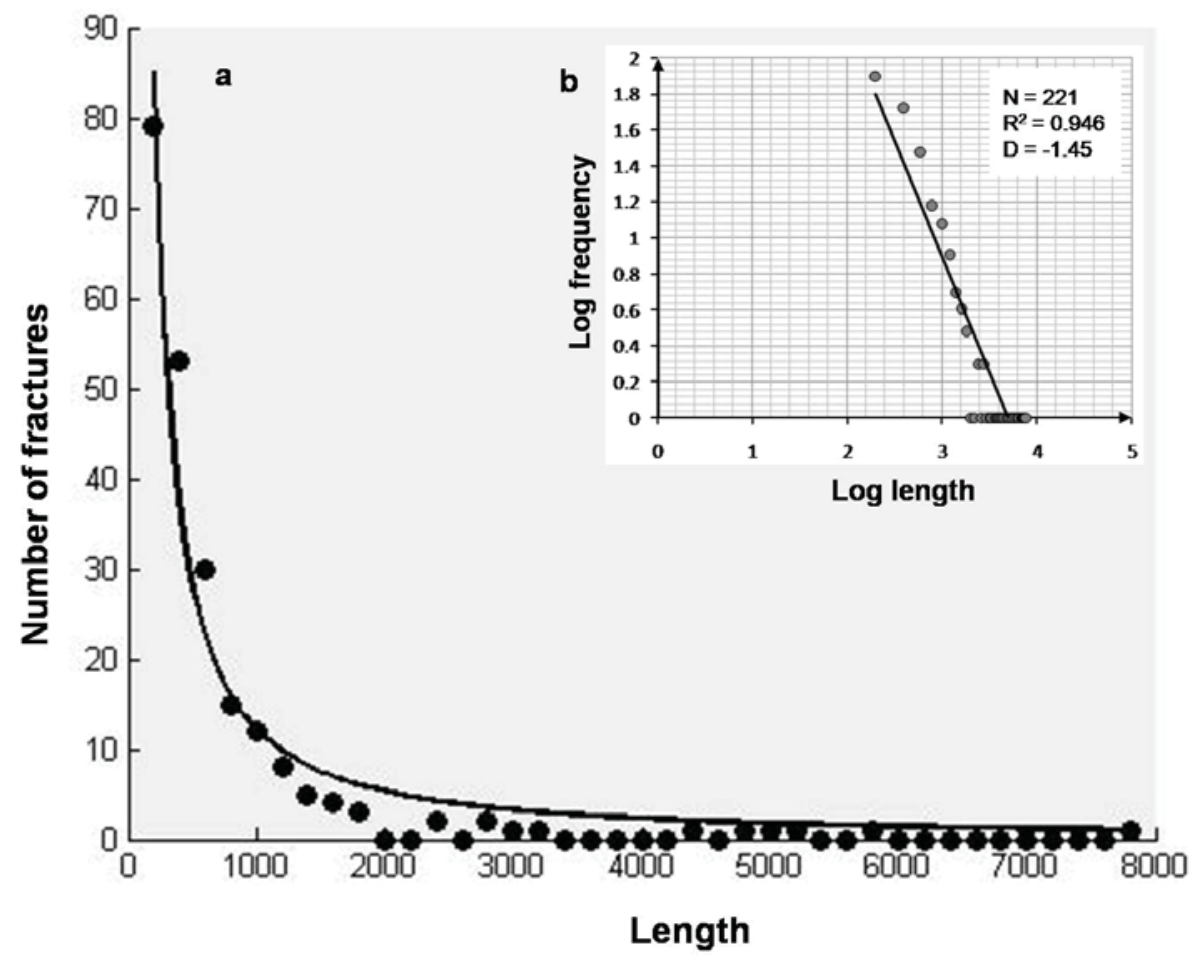

A log-log plot of $\mathrm{p}(\mathrm{x})$ in Equation (3) yields a straight line, but with a shallower slope than for $\mathrm{p}(\mathrm{x})$ in Equation (1). In the cumulative frequency distribution less data is obscured as noise than when using histograms. Cumulative power laws are commonly referred to as following Zipf's Law [4] or the Pareto Distribution [24]. 


\section{Measurements of Streets and Fractures}

\subsection{Streets}

To obtain quantitative data on street lengths and trends, we used Dundee, an old city with a current population of about 150,000, located along the north coast of a fjord named Firth of Tay in East Scotland (Figure 1). The oldest maps of the city date from around the end of the 16th century, at which time only about $1 \%$ of the current street pattern existed $[19,20]$. The city has clear boundaries, its overall shape is partly controlled by external constraints, primarily the coastline of the Firth of Tay, and the availability of GIS datasets makes it possible to carry out a detailed analysis of its street network. Additional reason for its selection is that the settlement has existed at least from medieval times and is historically interesting $[19,20]$.

In the analysis, there is a distinction between a named street and a street segment. A named street refers to an entire street as identified by a unique name or an ID. Thus, a named street commonly consists of many street segments and begins and ends where different street names take over. A street segment is normally just a part of a named street and is defined as the distance from one junction to the next one. Data on named streets are less accurate than data on street segments because some names in the databases may be missing or incorrect. However, both named streets and street segments are analysed in this paper.

\subsection{Fractures}

There are many striking similarities between crustal fracture networks in active areas and street networks (Figure 1). First, most crustal fractures and streets are composed of segments and many major fractures (and all major streets) have names. Second, both streets and fractures from parts of systems or networks that evolve and expand through time. Third, the networks of street and fractures are confined to certain areas of certain shapes at any particular time, and their main trends follow roughly normal distributions. Fourth, the length ranges are similar: from $3 \mathrm{~m}$ to $3023 \mathrm{~m}$ for the streets and from $40 \mathrm{~m}$ to $7736 \mathrm{~m}$ for the fractures. Fifth, the lengths of both streets and fractures follow power-law size distributions.

Street segments are the distances between junctions. For fractures, segments are either the distances between points of linkages or the distances between junctions. The main function of a street segment is to channel traffic flow which, in turn, is fundamentally analogous with, and often modelled as, fluid transport. Similarly, most crustal fractures, at various scales, transport fluids while they form parts of active networks. The analogy goes further. Both for streets and fractures, a certain energy is needed for their unit extension. Energy is needed for the extension (construction) of a street of a given type [25]. This energy is provided through human operations. Similarly, for a rock fracture energy is needed to overcome the surface energy of the rock, and this energy derives from the elastic potential energy stored in the rock before fracture propagation [26]. This energy is provided through natural processes related to stresses and crustal movements that are primarily generated by external tectonic forces at plate boundaries.

The driving forces of the street network of a city are partly internal (socio-economic), primarily the pressure of its growing population and wealth, and partly external (geographical/geological), 
particularly the constraints set by landscape factors. Since landscape factors are largely controlled by crustal weaknesses, primarily fractures, there may often be a clear correlation between the shape of a city controlled by its landscape factors and the fracture pattern of that part of the Earth's surface within which the city is located.

Many, and perhaps most, cities are controlled by comparatively old landscapes: the ages of the fractures controlling the river channels, the valleys, the mountain slopes, and the coastlines may be of the order of thousands or millions of years. Many old fractures are still weaknesses that are easily eroded and thereby maintain their control of the present landscape, but they do not, in their current state, provide clear indications as to how they initiated and evolved. To understand the evolution of crustal fractures for comparison with man-made lineaments such as streets, it is better to study fractures in tectonically active areas (Figure 1). The best such areas are the boundaries between the tectonic plates that constitute the Earth's surface shell, the lithosphere, some of which are characterised by rift zones.

Here we focus on the rift zone in Southwest Iceland (Figure 1), a well-studied zone [27-29] where fracture development is monitored through geodetic studies [30] and the properties of the rocks hosting the fractures are well known [26]. All the fractures are comparatively young (less than 10,000 -year-old) and form networks (swarms) that are still growing.

\subsection{Methods of Measurement}

The street/fracture trend variations are presented with rose diagrams (Figures 3-5). Rose diagrams are used to show the trend of either certain processes, such as wind directions at a certain locality over a certain period (a wind rose), or of certain lineaments such as rock fractures or streets [31,32]. For lineaments, such as streets and fractures, rose diagrams show the frequency of lineaments in a certain direction (orientation), that is, within a certain class or bin. Here the class or bin widths used are $10^{\circ}$ and the length of each sector or bin is a measure of the number or frequency of fractures/streets that fall into that bin. Our analysis of the lineament trends, represented by rose diagrams, used the program GEOrient [33].

There are two types of trend data: directional and oriented. In directional data we can distinguish one end of the lineament from the other, or left from the right, such as for flow in a river or a dominating wind direction. Oriented data, by contrast, relate to phenomena without a directional distinction, such as crustal fractures or streets in a city [31]. Thus, if the data is directional then the rose diagram shows a unidirectional or asymmetric trend distribution; if the data is oriented the rose diagram shows a bidirectional or symmetrical trend distribution. For directional data the measured data azimuths range from 0 to $360^{\circ}$. For oriented data, however, the opposite directions (in classes or sectors), $180^{\circ}$ apart, are equivalent. Here we use oriented fracture and street data so that the rose diagrams show bidirectional or symmetric trend distribution on a complete circle.

Rose diagrams can be made using either weighted or non-weighted data (Figures 3-5). The trends of streets are non-weighted when their lengths are not considered so that short streets and long streets have equal weight in the rose diagram. By contrast, when the street length is weighted by the length of the shortest street, more weight is given to the long streets because they consist of many short segments. We use standard regression methods for calculating the power laws in the ordinary plots as 
well as in log-log plots (Figure 2). Cumulative distributions [Equations (2) and (3)] are used to show the power-law properties of street and fracture lengths. From the slope of the straight lines on the log$\log$ plots (Figure 2), we calculate the scaling exponents of the power laws.

Figure 3. The street network of Dundee used in the present study. The rose diagrams are for all the street segments (6004) and all the named streets (1554). The weighted data take the street lengths into account, that is, give more weight to long streets in the roses, whereas the non-weighted data do not.
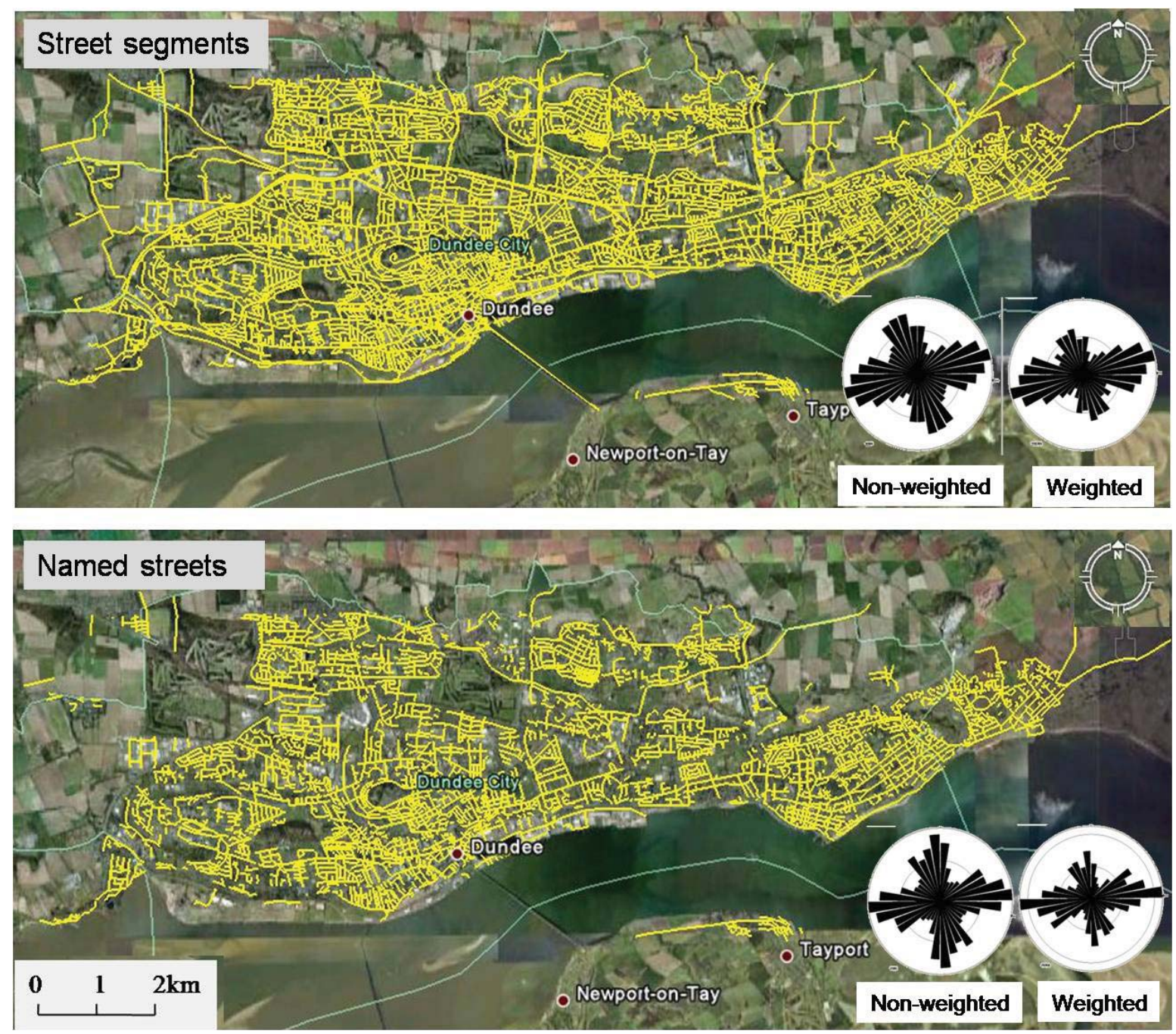

\section{Street Trends and Lengths}

\subsection{Variation in Street-Segment Trends within Dundee}

A total of 6004 street segments and 1554 named streets were measured. Each rose diagram in Figure 4 shows the orientation of street segments within a circle (a subset) using class limits (aggregations) of 10 degrees. We choose the subsets according to three criteria: (1) The number of streets should be similar in all the subareas (for each subset, the average number of measured street segments is 858). (2) All the subareas should be of a similar size. And (3) the subsets should reflect the changes in trend of the coastline. 
Figure 4. Variation in street trend for the part of the city close to, and at, the coast. Each rose (1-7) on the image presents the trend within the indicated chosen part of the city. On the image the data are non-weighted, but below the image the data are weighted.

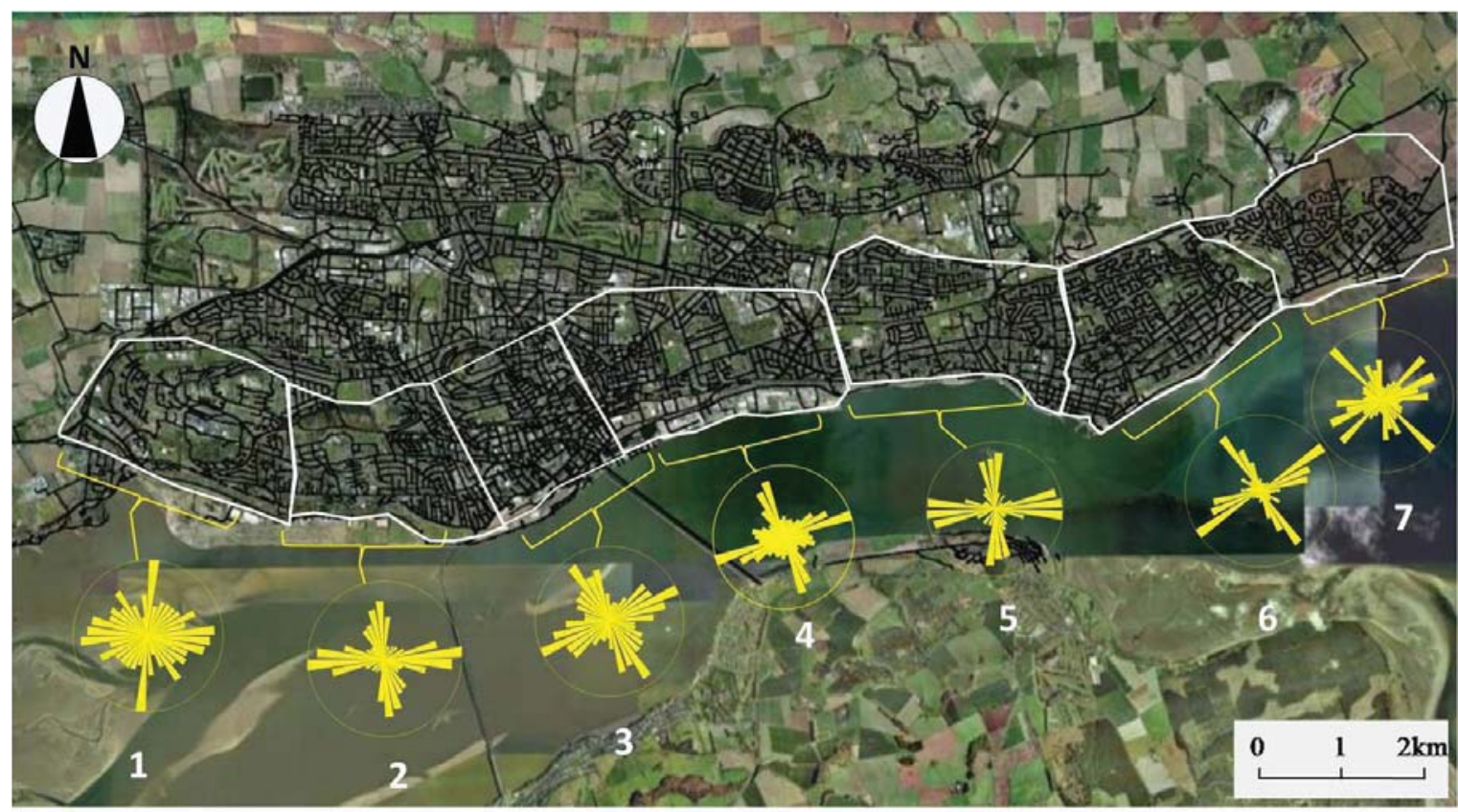

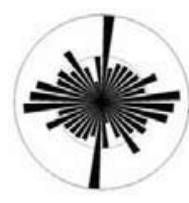

1

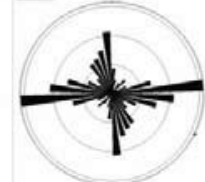

2

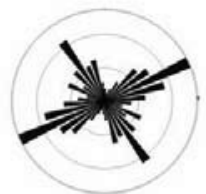

3

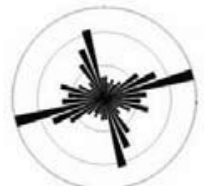

4

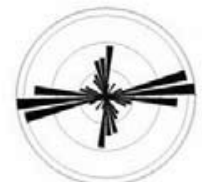

5

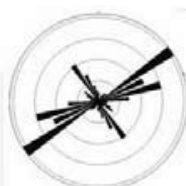

6

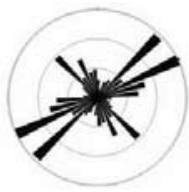

7

There are two main street trends: one is roughly north-south (strictly, trending north-northwest to south-southeast) the other roughly east-west (strictly, trending east-northeast to west-southwest) (Figure 3). The north-south trend is coast-perpendicular, the east-west trend coast-parallel, and both trends change with changes in the direction of the coast line. For example, the coastline and the coast-parallel street segments become east-northeast trending towards the east part of the city (Figure 4). At the same time, the northerly trending streets remain orthogonal and thus become north-northwest trending towards the eastern part of the city. There are also very significant changes at the lateral (east-west) ends of the city which are partly attributable to many streets in these parts being roughly perpendicular to the curved boundary of the city at these localities (Figures 1, 3 and 4).

At the lateral ends of the city, where the city boundary is curved (Figures 1 and 4), the weighted and non-weighted segment trends are very similar (Figure 4), indicating that the segments trending in the various directions have similar lengths. In the weighted data, the coast-parallel streets dominate (Figure 4), showing that they are, on average, longer than the coast-perpendicular streets.

The coastal effects on the street network of Dundee are thus clear as regards three factors. First, one of the two dominating street trends follows the coastline of the Firth of Tay very closely (Figure 1). The trend of the coastline itself is partly controlled by crustal fractures which form the part of a major fault zone [34]. Second, the streets parallel with the coastline are, on average, longer than the streets perpendicular to it. This is presumably because the city originated at the coast, at the first useable 
harbour, and subsequently grew partly inland but primarily along the coast. Third, the overall shape of the city is largely controlled by the coastline which has acted as a major external constraint on the city shape.

\subsection{Variation in Named-Street Trends within Dundee}

When analysing the trends of the 1554 named streets, we divided the studied part of the city into four subareas, rather than the seven for street segments, for two reasons. First, we wanted to have a reasonably large number of streets in each subarea (Figure 5). Second, for the named streets, the analysed four parts cover the whole width of the city and thus focus somewhat less on the coastal areas than the seven street-segment parts (which cover primarily the near-cost parts of the city). Each rose represents, on average, 388 named streets, the street orientation being in classes each of which spans 10 degrees (the $10^{\circ}$-class limits).

Figure 5. Comparison between the non-weighted (upper rose diagrams) and weighted (lower rose diagrams) of the trends of 1554 named streets along the coast of Dundee, divided into four subareas.

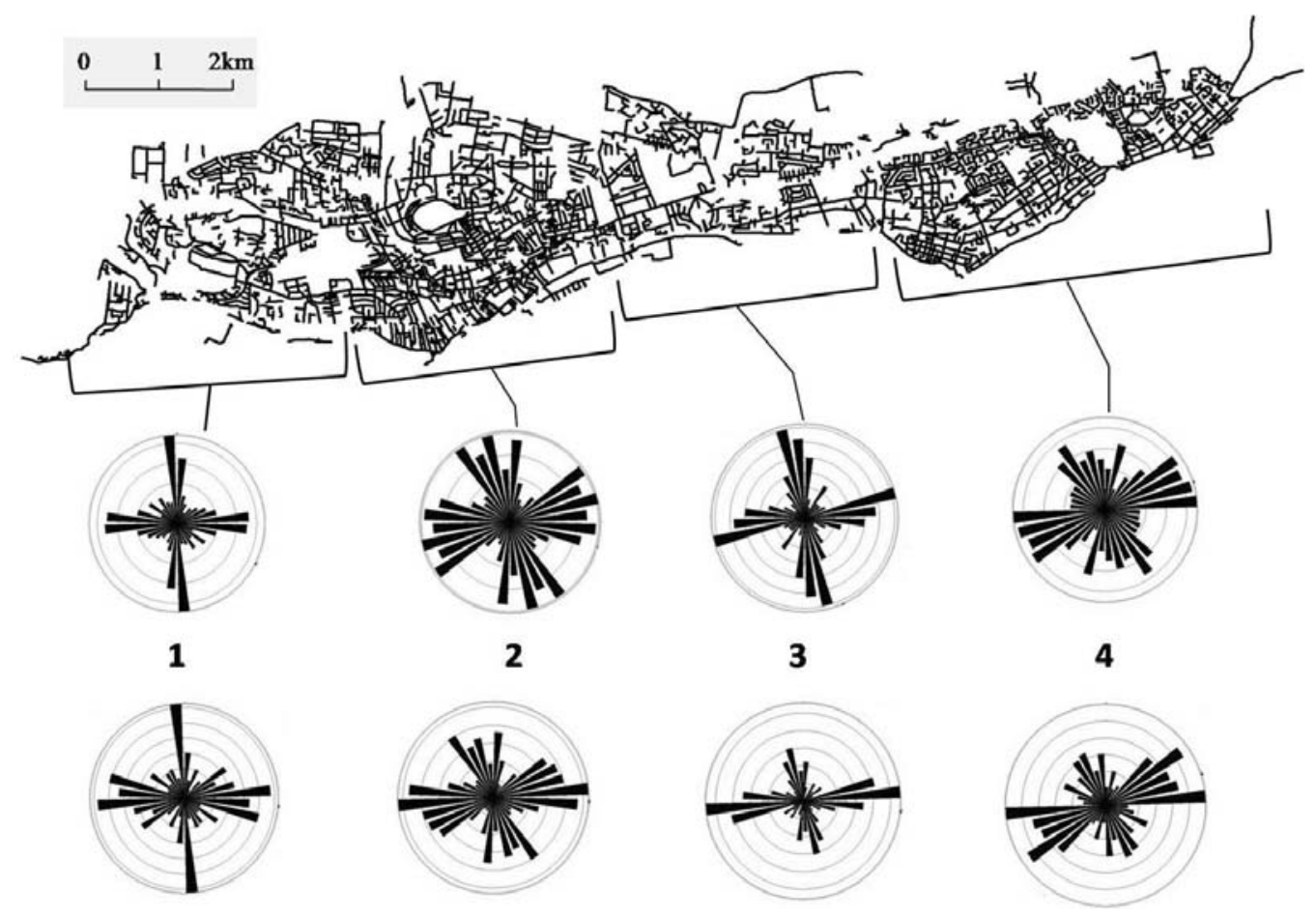

As for the street segments, the coast-parallel named streets are, on average, longer than the coastperpendicular streets (Figure 5) and show wider trend distributions at the lateral ends of the city than in its central parts. Also, the weighted and non-weighted data show similar trend distributions at the lateral ends, indicating that all the named streets in these parts have roughly equal lengths (Figure 5).

\subsection{Normal Distribution for the Main Street Trends}

We define certain sectors, that is, trend ranges, around each of the main orthogonal trends and calculate the mean trend of that sector (Figure 6). 
Figure 6. Frequency distributions of selected street segments (A and B) and selected named streets ( $\mathrm{a}$ and b) in Dundee. (A) and (a) represent coast-perpendicular and (B) and (b) coast-parallel streets. The selected parts of the rose diagrams are indicated (inset) by red, dotted sectors.


The results for the city as a whole show that the street-trend distributions follow approximately normal curves (Figure 6). We also found (not shown here) that that the two main (orthogonal) street trends in each of the studied subareas of street segments (Figure 4) approximately follow normal distributions, both as regards the coast-parallel and coast-perpendicular trends.

The mean trend of both the coast-parallel and the coast-perpendicular trends in each of the subareas (Figure 4) can now be calculated. As an example, the mean trends (azimuths, degrees) of the coast-parallel segments in the areas numbered 1-7 in Figure 4 are as follows: 105.7, 90.9, 52.5, 64.5, 89.3, 59.6, and 53.5. Clearly, the mean trends reflect the change in the general trend of the coastline. 


\subsection{Power Law Street-Length Distributions}

The cumulative frequency distributions of the length of all the measured streets in Dundee are shown in Figures 7-10. For the 6004 street segments the minimum length is $3 \mathrm{~m}$ and the maximum $2249 \mathrm{~m}$, whereas for the named streets (1554 data) the minimum length is $15 \mathrm{~m}$ and the maximum $3023 \mathrm{~m}$. The street segments and named streets both show power-law frequency distributions, in accordance with Equation (1).

Figure 7. All street segment lengths (6004) in Dundee. (a) An ordinary power-law frequency plot of all the street segments. (b) A single-line log-log plot of the whole population. (c) A double-line (double power law) plot of all the street segments.

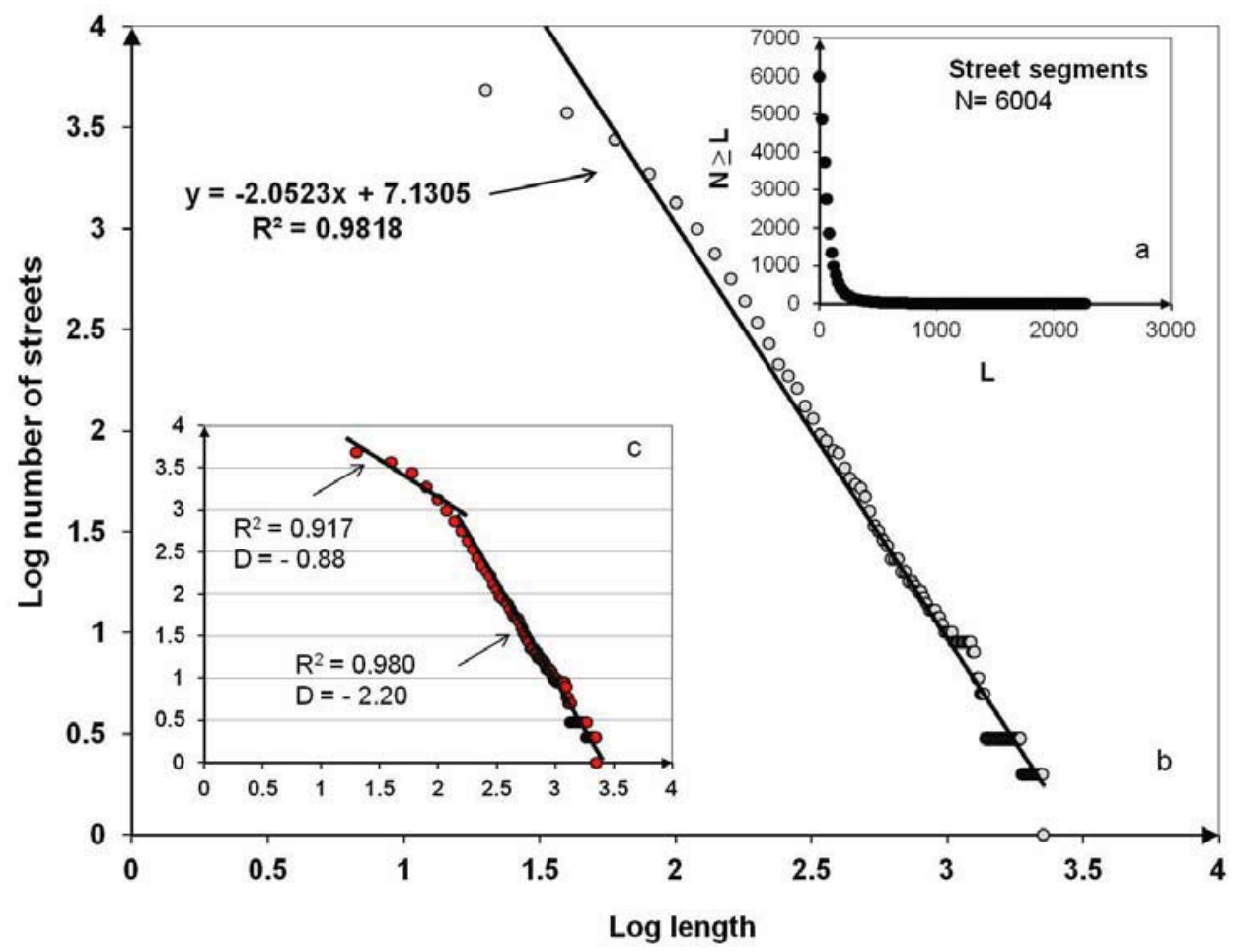

The length distributions (Figures 7a and 8a) for both segments and named streets seem reasonably close to following power laws. This applies also to selected streets from the two main orthogonal trends (Figures 9 and 10). On log-log plots, however, the deviations from the straight line are large and two straight lines (two power laws, Figures 7c, 9c1,c2), or, occasionally, three straight lines (Figures $8 \mathrm{c}, 10 \mathrm{c} 1, \mathrm{c} 2$ ), fit the data much better, suggesting that both segments and named streets follow power laws that have different slopes (scaling exponents) for different street length ranges. Different slopes of these kinds, referred to as double scaling laws when involving two straight lines, are observed in many power-law data sets [35], including those on fractures [36,37]. 
Figure 8. All named-street lengths (1554) in Dundee. (a) An ordinary power-law frequency plot of all the named streets. (b) A single-line log-log plot of the whole population. (c) A two-line plot of all the street segments.

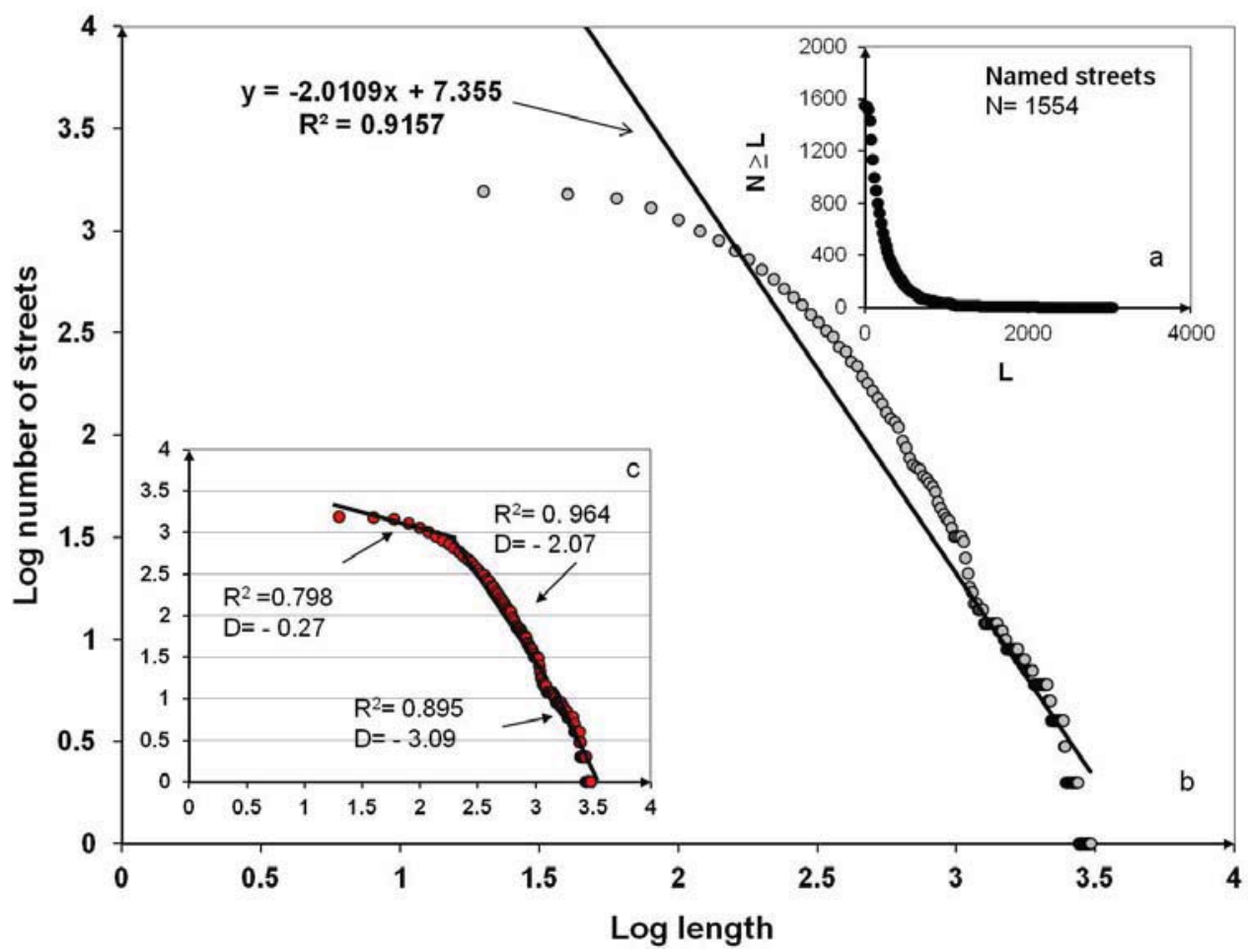

Figure 9. Length distribution of the street segments as selected in Figure 6, that is, coastparallel ( $A, 2041$ segments) and coast-perpendicular ( $B, 1589$ segments). (a) Ordinary power-law frequency plots of populations $A$ and $B$. (b) Single-line $\log -\log$ plots of $A$ and $B$. (c) Double-line plots of the populations $A$ (diagram c1) and $B$ (diagram c2).

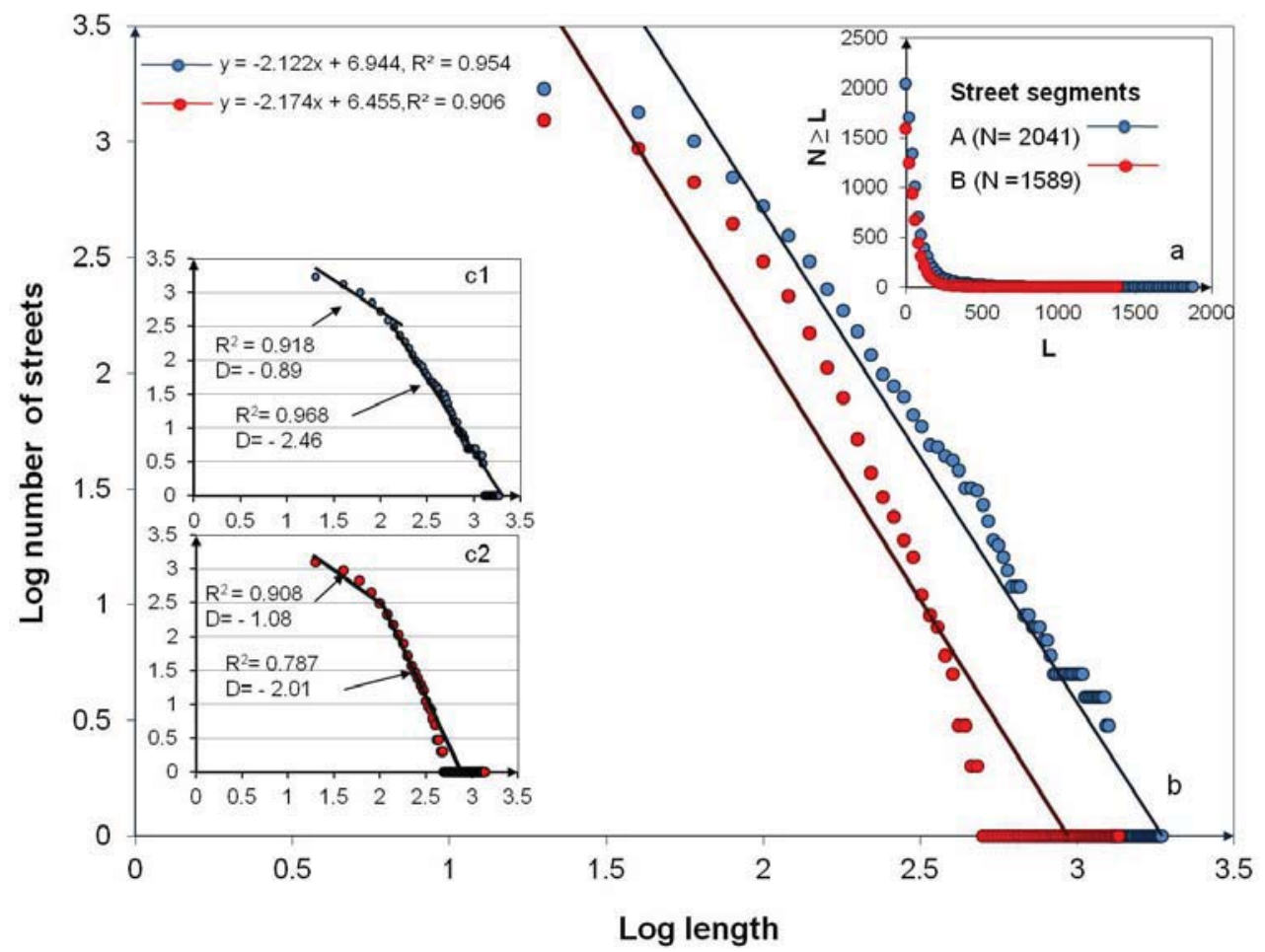


Figure 10. Length distribution of named streets as selected in Figure 6, that is, coast-parallel ( $a, 290$ named streets) and coast-perpendicular (b, 411 named streets). (a) Ordinary powerlaw frequency plots of populations $a$ and $b$. (b) Single-line log-log plots of populations $a$ and $b$. (c) Three-line plots of populations $a$ (diagram $\mathrm{c} 1$ ) and $b$ (diagram c2).

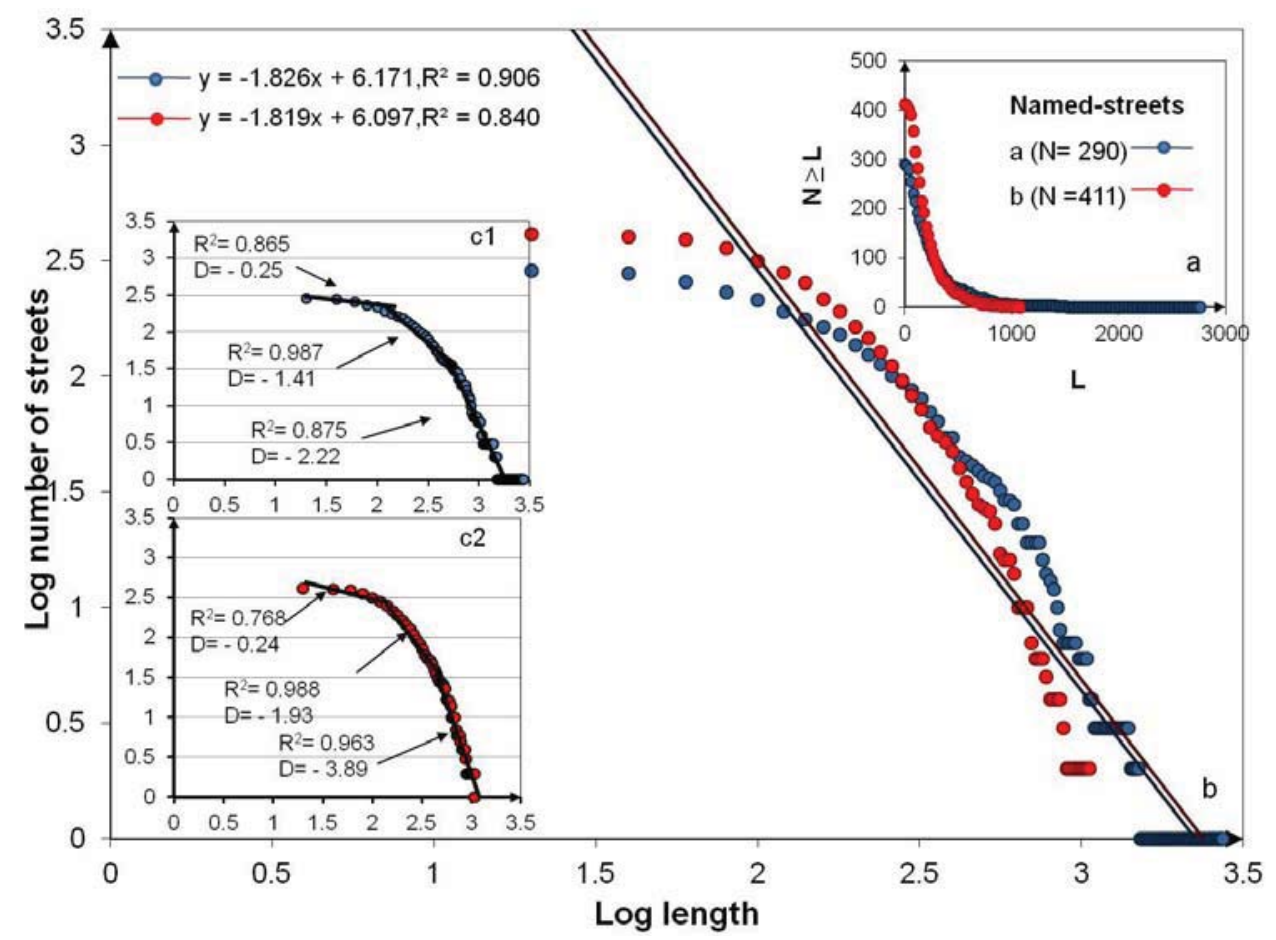

\section{Fracture Trends and Lengths}

All the 221 fractures analysed in this paper were collected from two networks or swarms in the active rift zone of Southwest Iceland, the Thingvellir Swarm and the Vogar Swarm. The Thingvellir swarm contains 101 fractures, the Vogar Swarm 120 fractures. Both swarms are elongated and form parts of larger volcantectonic systems, roughly elliptical in shape (Figure 1). The Vogar Swarm itself is about $80 \mathrm{~km}^{2}$ and the Thingvellir Swarm about $120 \mathrm{~km}^{2}$. All the fractures are generated in the same tectonic regime, located in rocks of the same age and with the same mechanical properties (basaltic pahoehoe lava flows about $10 \mathrm{ka}$ old), and are of the same two basic types, namely tension fractures (tensile cracks) and normal faults (shear cracks). They may therefore be analysed as a single population. When all the fractures are grouped together, their trends follow approximately a normal distribution (Figure 11). The northeast peak trend is perpendicular to the local tensile stress although somewhat oblique to the regional direction of the spreading vector responsible for the tectonic plates moving apart in Iceland (Figure 1). 
Figure 11. Trend (azimuth) distribution of all the 221 rock fractures used in the present study.

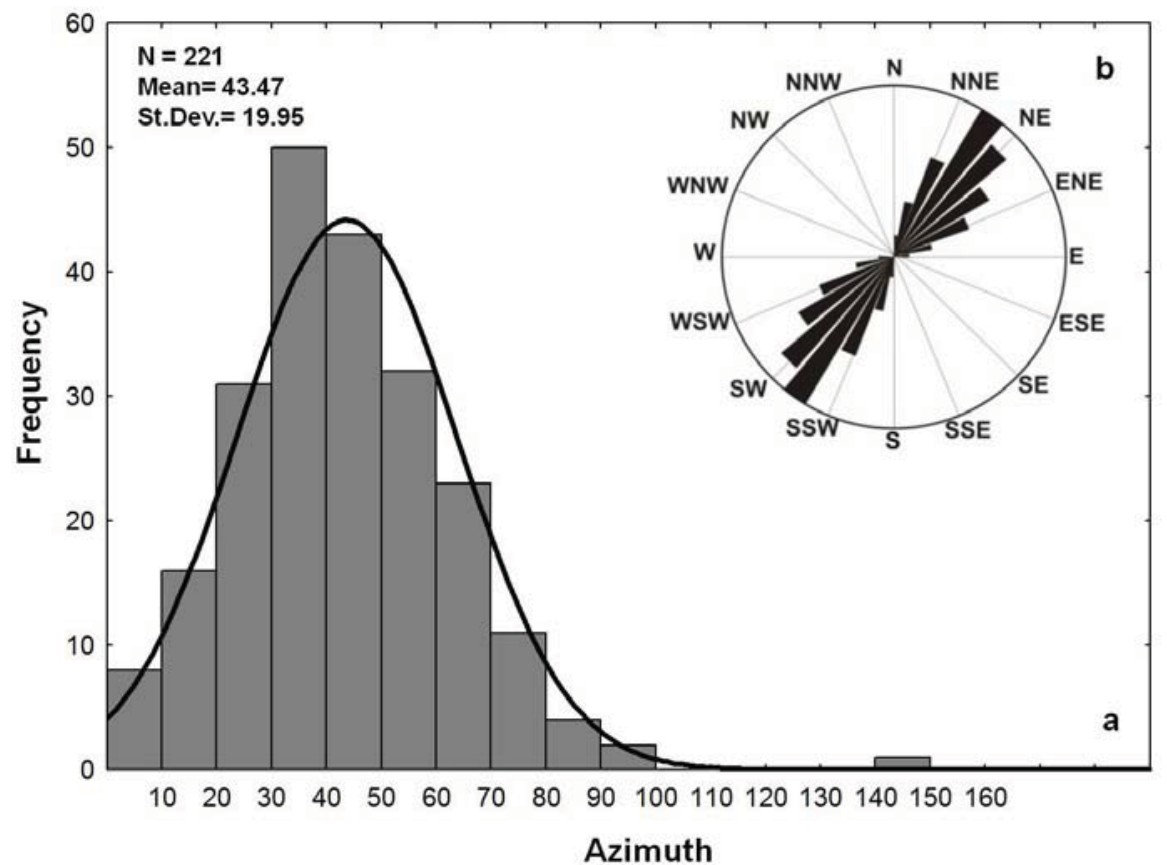

The lengths of the fractures, measured in the field (using a tape) and from aerial photographs (using stereoscopes and micrometers), range from $40 \mathrm{~m}$ to $7,700 \mathrm{~m}$ with an arithmetic average of $617 \mathrm{~m}$ ("average" is, of course, not a very meaningful parameter for a power-law distribution but useful in this context). The length distribution of all the fractures follows a power law, as indicated in the bin (histogram) plot in Figure 2. However, in the log-log plot of all the fractures in Figure 12 there is an abrupt change in slope, a break, at a length of 400-600 m.

All the fractures are tension fractures and normal faults, both of which trend in a direction that is perpendicular to the maximum tensile principal stress at the time of fracture formation. Since the fractures are vertical at and close to the surface, the maximum tensile stress is horizontal and perpendicular to the fracture trend. Tension fractures form as a result of absolute tensile stresses, that is, when a crustal segment is ruptured by tensile stresses which, in turn, are generated by the divergent movement of the lithospheric plates $[29,30]$. The movement or displacement across a tension fracture plane is in a direction perpendicular to the fracture plane and is generated by stresses that act perpendicular or normal to the plane of the fracture, normal stresses.

By contrast, all faults (earthquake fractures) are generated by shear stresses, that is, stresses that act parallel to the fracture (fault) plane. The movement or displacement across the fault plane is thus in a direction parallel to the fracture walls. A fundamental change occurs in the mechanics of fracture formation once a tension fracture develops into a normal fault [26]. Some fractures are hybrid, that is, partly tension fractures and partly shear fractures, and referred to as mixed-mode fractures. These are common at the surface of rift zones where growing tension fractures gradually change into normal faults [26-28].

The break at the length of 400-600 m corresponds roughly to the change from pure tension fractures to mixed-mode fractures. The fractures are initially generated as pure tension fractures but when they reach a certain depth they must change into normal faults. This depth can be calculated 
from the Griffith theory of fracture development and is, for the Icelandic rift zone, most commonly about 300-400 $\mathrm{m}$ [26,38]. This also fits with the field observations which indicate that the tension fractures are on average $370 \mathrm{~m}$ long in the Vogar Swarm, whereas the pure normal faults, in the same swarm, are on average $1990 \mathrm{~m}$ long [38].

Similar abrupt changes in the slope of the straight line in a log-log plot of fractures have been observed elsewhere [36,37]. The results apply not only to plots of fracture lengths [36], but also to the distances between the fractures in profiles, that is, to fracture spacing [37]. Hatton et al. [36] studied fractures in Iceland, but in different areas and at different lengths scales from those in the present study. The breaks in the slopes of the fractures are thus likely to be related to changes in the types of fractures. This means that the different slopes on the log-log plots refer to different fracture populations.

Figure 12. Log-log plots of all the fractures (Figure 1). (a) The Vogar Swarm fractures. (b) The Thingvellir Swarm fractures. (c) A single-line plot of both the swarms combined. (d) A double-line plot of both swarms combined (a double power law).
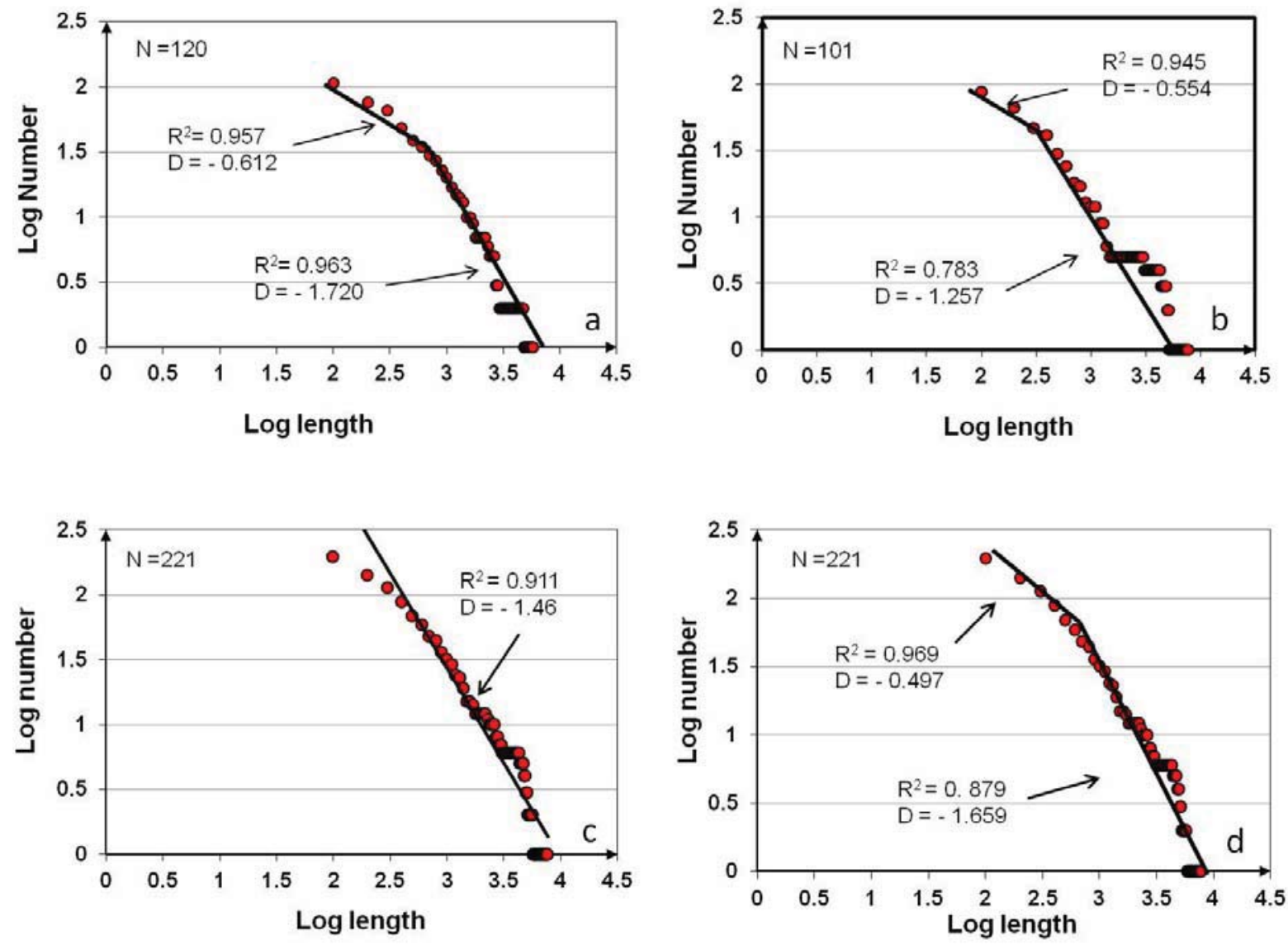

\section{Street Populations}

The breaks in the slopes of the straight lines on the log-log plots of the streets, we suggest, refer to different street populations (Figures 7-10). The street segments show a change in the slope of the straight line on the log-log plot at a length of about $140 \mathrm{~m}$ (Figures $7 \mathrm{c}$ and 9c). Segments that are shorter than about $140 \mathrm{~m}$ have a much shallower straight-line slope than those that exceed that length. 
The break occurs over a certain length range, so that the length at which the break occurs would more accurately be given as $140 \pm 15 \mathrm{~m}$. Nevertheless, it is clear that there is a break and the slopes of the lines and their scaling exponents change from 0.89 and 1.08 to 2.46 and 2.01, respectively (Figure 9c).

The named-street show two breaks (three straight lines) on the log-log plots (Figures 8c, 10c1,c2). The first break in slope occurs at the same length as that for the street segments, namely at about $140 \mathrm{~m}$. There the slope on the coast-parallel plot changes from 0.25 to 1.41 , whereas that on the coast-perpendicular plot changes from 0.24 to 1.93 (Figure 10c1,c2). These slope changes thus occur at the same length and are rather similar. The second break in slope, however, differs between the coast-parallel and the coast-perpendicular trends. For the coast-parallel trend, the second break in slope occurs at a length of $640 \mathrm{~m}$, where the slope changes from 1.41 to 2.22. For the coast-perpendicular trend, however, the break in slope occurs at $540 \mathrm{~m}$, where slope changes from 1.93 to 3.89 (Figure 10c).

We interpret these data so that the different slopes represent different street populations. The first population is composed of streets with lengths from $3 \mathrm{~m}$ to $140 \mathrm{~m}$, for the segments, and from $15 \mathrm{~m}$ to $140 \mathrm{~m}$ for the named streets. These differ somewhat as regards the minimum length — as expected, the minimum length for named streets is greater than that for segments - but otherwise this is a single population of short to very short streets. This population comprises primarily local streets (roads), including private lanes and alleys and cul-de sacs [39-41].

The second population is composed of two subpopulations. One consists of the street segments, the other of the named streets. The segment subpopulation ranges in length from $140 \mathrm{~m}$ to $1862 \mathrm{~m}$. For the coast-parallel segments $(\mathrm{D}=2.46)$ the maximum length is $1862 \mathrm{~m}$, whereas that of the coast-perpendicular segments $(\mathrm{D}=2.01)$ is $1377 \mathrm{~m}$. The coast-parallel segments thus reach greater lengths than the coast-perpendicular segments.

The second subpopulation consists of named streets ranging in length from about $140 \mathrm{~m}$ to $640 \mathrm{~m}$ for the coast-parallel streets and from $140 \mathrm{~m}$ to $540 \mathrm{~m}$ for the coast-perpendicular streets. Thus, at the lengths of $540-640 \mathrm{~m}$, there is a third population for the named streets, the slope of the straight line being $\mathrm{D}=2.22$ for the coast-parallel streets and $\mathrm{D}=3.89$ for the coast-perpendicular streets (Figure $10 \mathrm{c}_{1}, \mathrm{c}_{2}$ ).

We interpret the second population, including both subpopulations, as being primarily composed of local roads and collectors [40,41]. These include many unclassified streets as well as some C and B roads/streets in the British classification of roads.

The third population is primarily composed of long collectors as well as (rural) major and minor arterials. Most of these have traffic lights that stop the traffic at certain points and are thus not freeways. Many of these are primary and non-primary A roads as well as B roads in the British classification. The longest named street in the data set is about $2.7 \mathrm{~km}$. However, the named streets only include those streets that have proper names. Streets that are only identified with numbers (M, A, $\mathrm{B}$, etc.) do not have names and are therefore not included in the data set of named streets; however, they are included in the data set of segments. 


\section{Entropy and Street/Fracture Networks}

In classical thermodynamics, entropy (S), or rather (an infinitesimal) entropy change, dS is defined as [42-48]:

$$
d S \geq \frac{\delta Q}{T}
$$

where $\delta \mathrm{Q}$ is the energy (heat) received or absorbed by the system under consideration, $\mathrm{T}$ is the absolute (Kelvin) temperature at the time when that energy is received, and the entropy units are $\mathrm{J} \mathrm{K}^{-1}$. For a thermally isolated system $\delta Q=0$ so that:

$$
d S \geq 0
$$

a well-known version of the second law of thermodynamics. The entropy of a closed or an open system may decrease. But then the entropy of its surrounding must increase, and the total entropy of the system and its surrounding, during any particular process, will increase.

Entropy as defined above does not have an obvious application to street and fracture networks but does so when related to a probability. The entropy $\mathrm{S}$ of an isolated system in a given macrostate where all the probabilities are the same may be presented by the Boltzmann equation [43-48]:

$$
S=k \ln W=-k \ln p
$$

where $\mathrm{W}$ is the number of microstates (multiplicity) associated with that particular macrostate or, alternatively, the number of ways the objects or elements of a system can be arranged so as to reach the same total energy and $p=1 / \mathrm{W}$ is probability. For thermodynamic entropy, $k$ is Boltzmann's constant $\left(k_{B}=1.38066 \times 1023 \mathrm{~J} \mathrm{~K}^{-1}\right)$. For a general probability or frequency distribution, as in Equation (7), $k$ is commonly regarded as an arbitrary constant with a unit value $(k=1)$, in which case the entropy becomes dimensionless. The meaning of $k$ is explored further in Section 9.2.

For a general probability distribution, Equation (6) becomes the Gibb's entropy formula [44-49]:

$$
S=-k \sum_{i=1}^{t} p_{i} \ln p_{i}
$$

where $t$ is the number of distinct objects, components, or outcomes $(i=1,2,3, \ldots ., t)$, and $p_{i}$ is the probability of finding the system in its $i$-th macrostate, that is, it refers to the (energy-dependent) probabilities of the various microstates, namely:

$$
p_{i}=\frac{n_{i}}{N}
$$

where $n_{i}$ is the number of microstates in the $\mathrm{i}$-th macrostate, and the system has a total of $\mathrm{N}$ microstates. Equation (7) is analogous to the Shannon entropy equation in information theory [50] where, however, the logarithm used has a base 2 rather than the base e used in Equation (7).

When applied to street/fracture networks, $t$ in Equation (7) is the number of classes or bins that contain streets/fractures in the frequency distribution, that is, the number of bins with nonzero probabilities of streets/fractures. Also, $\mathrm{p}_{\mathrm{i}}$ is then the frequency or probability of streets/fractures belonging to the $\mathrm{i}$-th bin, that is, the probability of the $\mathrm{i}$-th class or bin $[21,44,49]$. When calculating 
the entropy using Equation (7) only those bins are included where there is at least one observed street/fracture, that is, where the probability of finding a lineament is greater than zero. By definition:

$$
\sum_{i=1}^{t} p_{i}=1
$$

The probabilities, as applied to streets/fractures in a population, are a measure of the chances of a randomly selected street/fracture from the population falling into a particular bin. The chosen bin width or size for grouping the lineament data affects the entropies calculated using Equation (7). Here, however, all the bin widths used for the street data are the same, namely $20 \mathrm{~m}$, and those for the fractures $100 \mathrm{~m}$.

If the distribution is uniform, all the bins occupied by streets/fractures have the same lengths (heights) and the entropy reaches its maximum value, which can be calculated either from Equation (6) or Equation (7) as:

$$
S=-k \ln t
$$

which is the same as Equation (6), just with a slightly different notation.

The rose diagrams (Figures 3-5) and the histograms (Figures 6 and 11) for azimuth show that streets and fractures follow close-to normal distributions as regards trend. The shape of a frequency (or probability) distribution is a measure of entropy. When there are no constraints, a peaked normal (Gaussian) distribution has comparatively low entropy whereas a flat distribution has high entropy. In the present context, as the distribution becomes flatter (more dispersed) it becomes less probable, when making a blind selection, that we would be able to specify from which trend class/bin in the histogram the lineament came.

Both the standard deviation $\sigma$ and the variance $\sigma^{2}$ are measures of the spread and thus the entropy of the probability/frequency distribution. Tables 1 and 2 give the standard deviations of the rose diagrams in Figures 3 and 6 and show that, generally, the standard deviations of all the populations are similar (between about 22 and 29 degrees). Entropy generally increases with the flatness, dispersal or spreading of a frequency distribution and thus with the increase in the variance or standard deviation. Therefore, if all the streets/fractures had the same trend, the entropy would be minimum, whereas if there was no preferred trend (all the classes or bins were equally high), the entropy would be maximum.

Because entropy in the probabilistic sense is an indication of the spread of any kind of frequency distribution, length distribution of lineaments is also a measure of entropy. To analyse further the entropy variation of the street/fracture patterns, we use Equation (7) to calculate the entropies associated with the various populations identified as well as the scaling exponents through Equation (1). The results are presented in Tables 1 and 2. We calculated the scaling exponent D and the entropy $\mathrm{S}$ for a total of 21 street populations; 12 for named streets and 9 for street segments. The scaling exponents and the entropies are compared in Figure 13. Here all the populations are plotted except the last one in Table 2 (named streets), the values of which $(\mathrm{D}=3.89, \mathrm{~S}=2.98)$ lie far outside the general range for unknown reasons.

The results show a clear positive correlation between the entropy and the scaling exponent for all the street/fracture populations (Figures 13 and 14): as the scaling exponent increases, so does the entropy. Rock-fracture experiments also show such a linear correlation: when the scaling exponent of 
an evolving set of fractures increases, so does the estimated entropy of the set [51]. Similarly, when the scaling exponent of an evolving fracture set decreases, the estimated entropy of the set also decreases.

Figure 13. Entropy versus scaling exponents (a) and length ranges (b) of street segments. Entropy versus scaling exponents (c) and length ranges (d) of named streets. For all illustrations, only the bold data in Tables 1 and 2 are included here, that is, the poor singleline fits for the whole populations are omitted.
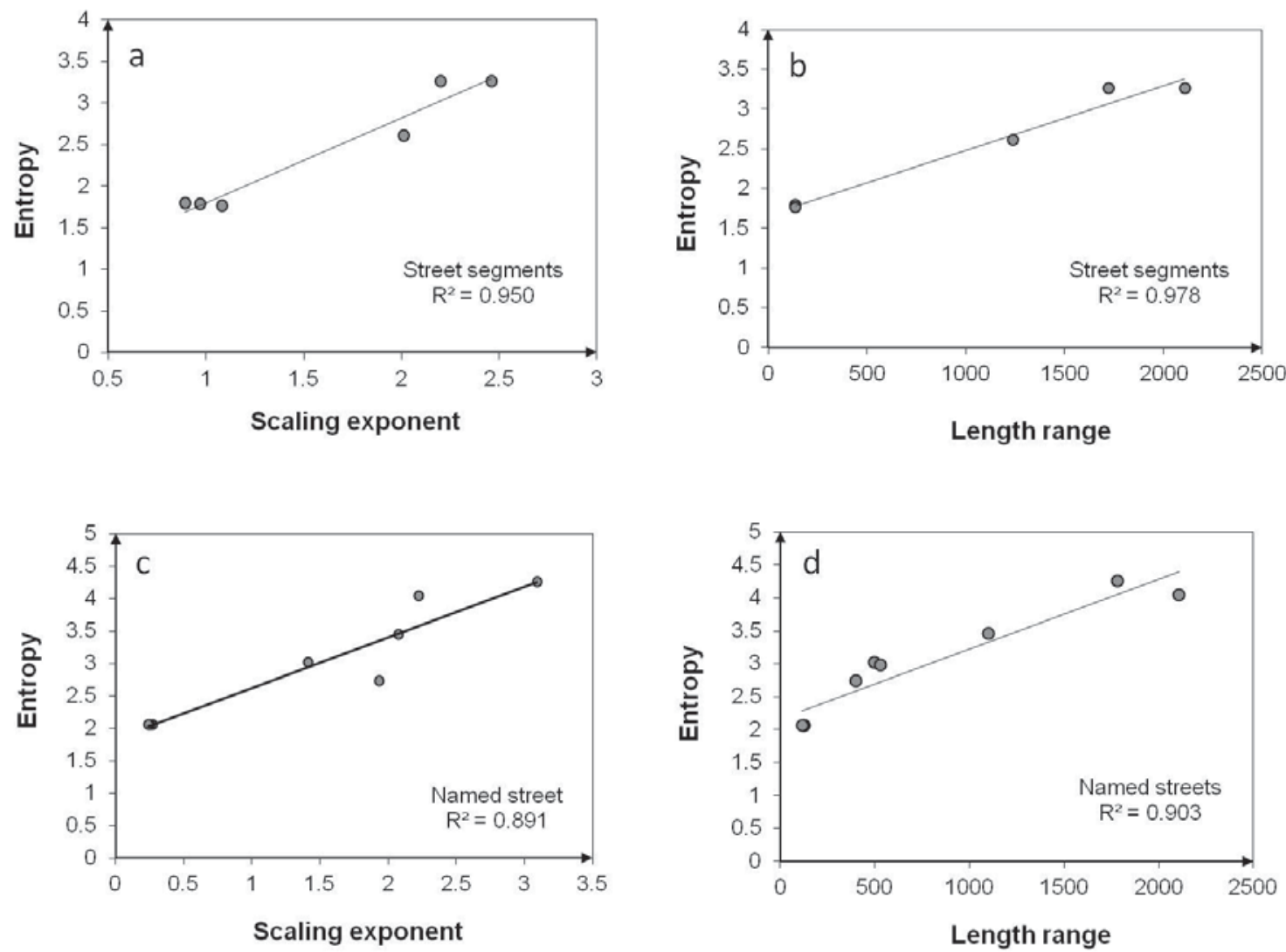

Conceptually, the changes in scaling exponent and entropy of fracture sets can be understood as follows. When the loading (stress, pressure, displacement) on a rock laboratory specimen, or a crustal segment, is increased fractures start to develop [26]. In the laboratory specimen, the fractures develop from pores (cavities) and crystals, whereas in the crustal segments they commonly develop from previously formed (existing) larger weaknesses such as the type of fractures known as joints [26]. It is from the existing weaknesses in the rock that the larger fractures develop and commonly generate patterns that are broadly similar to street patterns [52-55]. The development of fracture networks with similarities to street patterns is not limited to rocks: most solid materials when subject to sufficiently high loading develop similar fracture networks [56,57].

The fracture network may nucleate at a notch, an area of stress concentration, from which the fractures propagate and spread in various directions as the load is increased [52]. The fractures link up in a manner similar to street networks, with gradually longer fractures developing as the fractured area expands, until the specimen fails when it forms a through-going fracture (which is also analogous to reaching the percolation threshold [58]). Similarly, a street network may originate from the nucleus of 
the initial village which may be a natural harbour. Such is the case of Dundee, which gradually expanded from the harbour into, first, a village, then a town and then, eventually, a large city [19,20].

As the fracture network expands, that is the material damage increases and more fractures form and link together and the material approaches large-scale failure, the scaling exponent of the fracture population increases. For experiments on marble, the scaling exponent increases from about 1.7 to about 2.5, and for sandstone from 2.7 to 2.9, before specimen failure [52]. Recent experiments show that as the material damage increases, so does the entropy [59,60]. Similarly, for the fracture populations in Iceland there is a strong linear correlation between the entropy and the scaling exponents (Figure 14a).

A long power-law tail normally implies a more dispersed distribution (greater spreading) and therefore a comparatively high entropy. Thus, the entropy might be expected to vary positively with the length of the tail, that is, with the range in length (the difference between the maximum and the minimum length) of fractures within each population. To test this implication, we plotted the entropies of the fracture populations against their length ranges. The results (Figure 14b) show a very high linear correlation between the entropy and length range. This indicates that the calculated entropies (and scaling exponents) of the fracture populations may be regarded as a measure of the dispersion or disorder in fracture length in the populations as they develop and expand over time.

Figure 14. (a) Entropy versus fracture scaling exponent. (b) Entropy versus fracture length range. For both plots, the poor single-line fits for the whole populations are omitted (as in the plots in Figure 13).
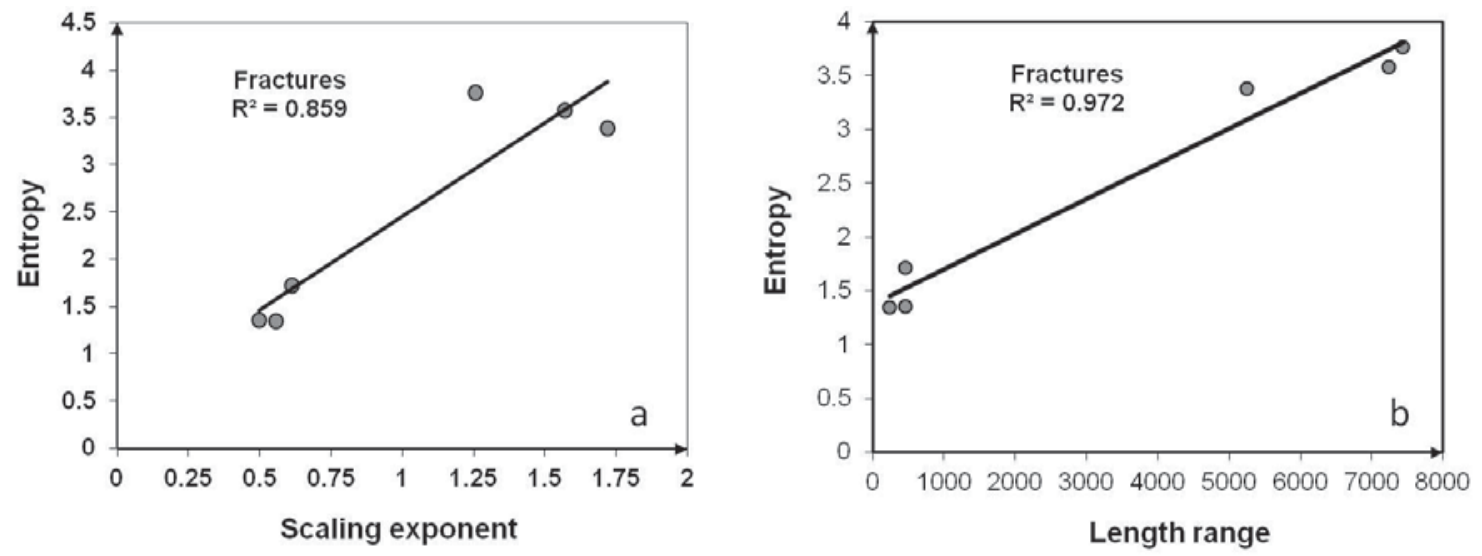

The analogy with the street populations is clear. The street network, like the fracture network, gradually expands from a nucleus (here the harbour). If the network remains unchanged as regards range in street length, then the scaling exponent (the straight-line slope on the log-log plot) and the entropy remain the same. If, however, the added short streets remain of the same length as the city expands but the maximum lengths of the added long streets increase, the length range would increase during the city evolution. By analogy with the fracture networks, the scaling exponents and the entropy are would then also increase. To test this, we plotted the entropies against the length ranges of the various street populations (Tables 1 and 2). The results (Figure 13b,d) show a clear positive linear correlation between entropies and the range in street length (again omitting the last population in Table 2). 
Table 1. Standard deviation, frequency (number), length range, scaling exponent (D), standard error on $D$, coefficient of determination $\left(R^{2}\right)$, and entropy (S) of the populations and subpopulations of coast-parallel and coast-perpendicular street segments.

\begin{tabular}{|c|c|c|c|c|c|c|c|c|}
\hline \multicolumn{9}{|c|}{ Street segments (trends and lengths) } \\
\hline Street population & Trend & Std.Dev. (Street trend) & Frequency & Length range (m) & Scaling exponent & S. Error & $\mathbf{R}^{2}$ & Entropy (S) \\
\hline \multirow{3}{*}{ Street segments } & \multirow{3}{*}{-------- } & \multirow{3}{*}{--------- } & 6004 & $3-2249$ & $\mathrm{D}=2.05$ & 0.112 & 0.982 & 2.50 \\
\hline & & & 5256 & $3-140$ & $\mathrm{D}=0.97$ & 0.027 & 0.919 & 1.78 \\
\hline & & & 748 & $140-2249$ & $\mathrm{D}=\mathbf{2 . 2 0}$ & 0.056 & 0.989 & 3.26 \\
\hline \multirow{3}{*}{ Coast-parallel } & \multirow{3}{*}{ A } & \multirow{3}{*}{22.146} & 2041 & $3-1862$ & $\mathrm{D}=2.12$ & 0.180 & 0.954 & 2.63 \\
\hline & & & 1736 & $3-140$ & $\mathrm{D}=\mathbf{0 . 8 9}$ & 0.072 & 0.917 & 1.8 \\
\hline & & & 305 & $140-1862$ & $\mathrm{D}=\mathbf{2 . 4 6}$ & 0.117 & 0.968 & 3.26 \\
\hline \multirow{3}{*}{ Coast-perpendicular } & \multirow{3}{*}{ B } & \multirow{3}{*}{24.679} & 1589 & $3-1377$ & $\mathrm{D}=2.17$ & 0.273 & 0.906 & 2.17 \\
\hline & & & 1440 & $3-140$ & $\mathrm{D}=\mathbf{1 . 0 8}$ & 0.087 & 0.908 & 1.76 \\
\hline & & & 149 & $140-1377$ & $\mathrm{D}=\mathbf{2 . 0 1}$ & 0.258 & 0.787 & 2.61 \\
\hline
\end{tabular}

Table 2. Standard deviation, frequency (number), length range, scaling exponent (D), standard error on $D$, coefficient of determination $\left(R^{2}\right)$, and entropy (S) of the populations and subpopulations of coast-parallel and coast-perpendicular named streets.

\begin{tabular}{|c|c|c|c|c|c|c|c|c|}
\hline \multicolumn{9}{|c|}{ Named street (trends and lengths) } \\
\hline Street population & Trend & Std.Dev. (Street trend) & Frequency & Length range (m) & Scaling exponent & S. Error & $\mathbf{R}^{2}$ & Entropy (S) \\
\hline \multirow{4}{*}{ Named segments } & \multirow{4}{*}{-------- } & \multirow{4}{*}{------ } & 1554 & $15-3023$ & $\mathrm{D}=2.01$ & 0.249 & 0.915 & 3.54 \\
\hline & & & 654 & $15-140$ & $\mathrm{D}=\mathbf{0 . 2 7}$ & 0.019 & 0.798 & 2.06 \\
\hline & & & 886 & $140-1240$ & $\mathrm{D}=\mathbf{2 . 0 7}$ & 0.087 & 0.964 & 3.45 \\
\hline & & & 14 & $1240-3023$ & $\mathrm{D}=\mathbf{3 . 0 9}$ & 0.112 & 0.895 & 4.26 \\
\hline \multirow{4}{*}{ Coast-parallel } & \multirow{4}{*}{$\mathrm{A}$} & \multirow{4}{*}{28.965} & 290 & $15-2746$ & $\mathrm{D}=1.83$ & 0.237 & 0.906 & 3.59 \\
\hline & & & 114 & $15-140$ & $\mathrm{D}=\mathbf{0 . 2 5}$ & 0.044 & 0.865 & 2.06 \\
\hline & & & 153 & $140-640$ & $\mathrm{D}=1.41$ & 0.029 & 0.987 & 3.02 \\
\hline & & & 23 & $640-2749$ & $D=2.22$ & 0.147 & 0.875 & 4.04 \\
\hline \multirow{4}{*}{ Coast-perpendicular } & \multirow{4}{*}{$\mathrm{B}$} & \multirow{4}{*}{23.768} & 411 & $24-1071$ & $\mathrm{D}=1.82$ & 0.312 & 0.840 & 3.13 \\
\hline & & & 157 & $24-140$ & $\mathrm{D}=0.24$ & 0.047 & 0.768 & 2.06 \\
\hline & & & 231 & $140-540$ & $D=1.93$ & 0.024 & 0.987 & 2.73 \\
\hline & & & 23 & $540-1071$ & $D=3.89$ & 0.059 & 0.968 & 2.98 \\
\hline
\end{tabular}




\section{Tests of the Power-Law Models}

It is well known that, theoretically, there is an infinite number of functions that can fit a given data set. For example, if we have $\mathrm{N}$ data points in a set, we can fit an $(\mathrm{N}-1)$ degree polynomial perfectly through all the points [62-65]. Such a fit, however, has little physical meaning if there is no underlying theory that would favour a polynomial as a model (a fit) over other functions. When we fit functions to experimental and observational data, there are many factors to consider in addition to the 'goodness of fit'. These factors include the theoretical framework within which the data were obtained and the relative 'simplicity' of the functions (a criteria, however, for which there is still not much agreement) that fit the data.

A log-log plot that yields a straight line is regarded as an indication that the data follow a power-law size distribution. However, even if the data follow a power-law distribution, it does not follow that the power law necessarily provides the best model or fit for the data. Many authors have suggested methods for testing how well power laws fit datasets in comparison with other functions (e.g., [9]). For a standard least-squares linear regression the goodness-of-fit between the calculated line and the actual data is obtained by considering the residuals of the curve-fitting procedure, that is, the vertical distances of all the points from the regression line. If the fit is good the residuals should ideally have (1) a mean of zero, (2) have a random distribution on either side of zero (the horizontal axis in Figures 15 and 16), that is, show no obvious structure, and (3) have a normal distribution centred on zero (the horizontal axis).

Figure 15. Test of a power-law fit for street segments. (a) Residuals for the single-line power law fit in (b) for all the street segments (6004). (c) For comparison, a parabola fit to all the street segments.

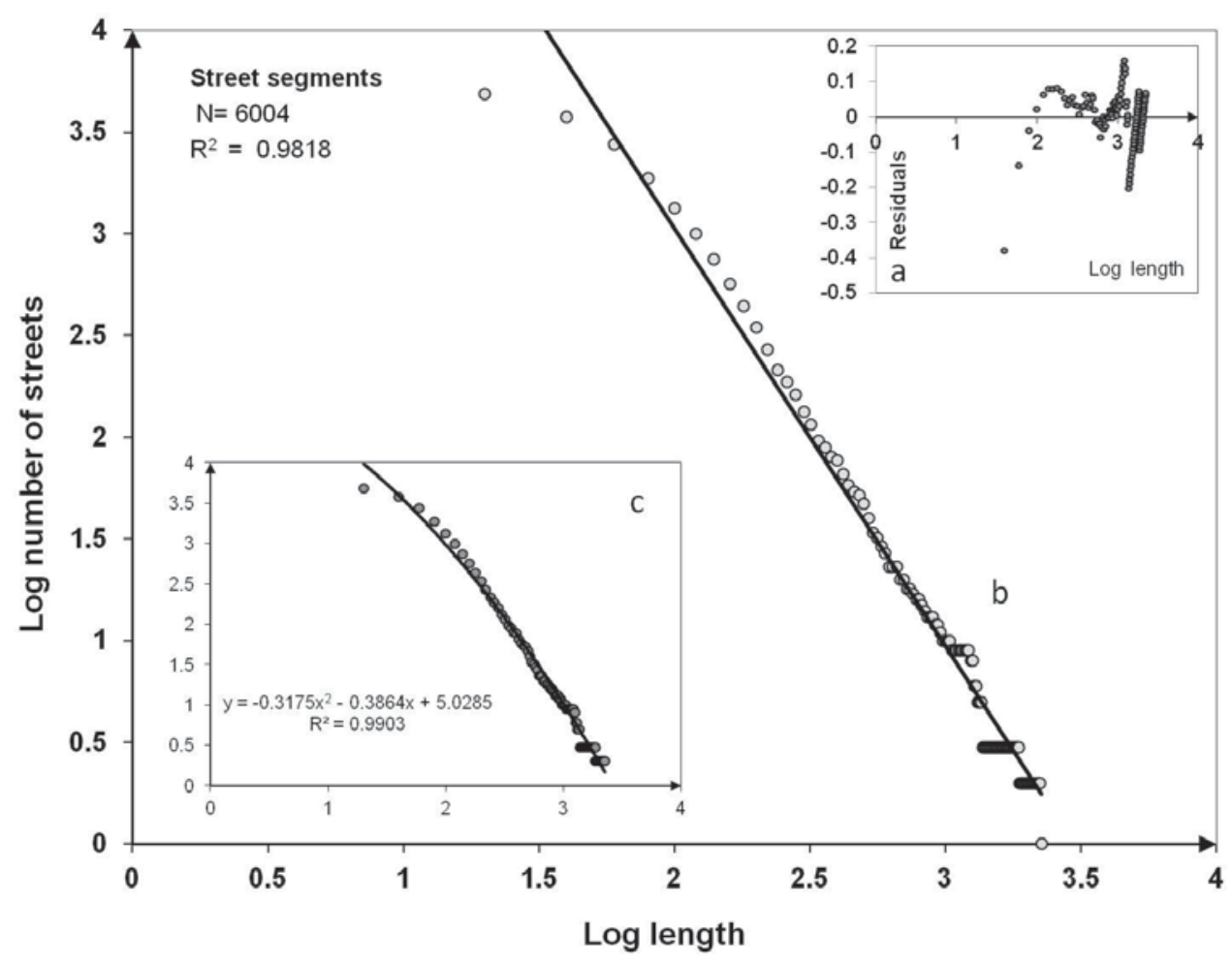


We calculated the residuals for the power-law regression lines for the whole populations of street segments and named streets in Dundee. Then we compared the results with the fit with a parabola. The results (Figures 15 and 16) show as follows. For the street segments the mean of the residuals is -1.357 , the standard deviation is 0.078 , and the range (the difference between the maximum and minimum residual) is 0.538 (Figure 15). The distribution of residual values (Figure 15a), when analysed in terms of a histogram (not shown here), is seen to be close to a normal distribution with a peak (mode) at around 0.1 The value of $\mathrm{R}^{2}$ may be regarded as a measure of the goodness-of-fit. For a parabola-function, we get $\mathrm{R}^{2}=0.9903$ whereas for the power law its is $\mathrm{R}^{2}=0.9818$. Clearly, both the power law and the parabola-function fit the dataset well.

For the named streets the mean of the residuals is 1.575 , the standard deviation is 0.21 , and the range is 1.388 (Figure 16). The distribution of residual values (Figure 16a), when analysed as a histogram (not shown here), is, again, not far from a normal distribution and with a peak (mode) at around 0.1 . For a parabola-function, we get $\mathrm{R}^{2}=0.9892$ whereas for the power law $\mathrm{R}^{2}=0.9157$. Clearly, both the power law and the parabola-function fit the dataset well.

Figure 16. Test of a power-law fit for named streets. (a) Residuals for the single-line power law fit in (b) for all the named streets (1554). (c) For comparison, a parabola fit to all the named streets.

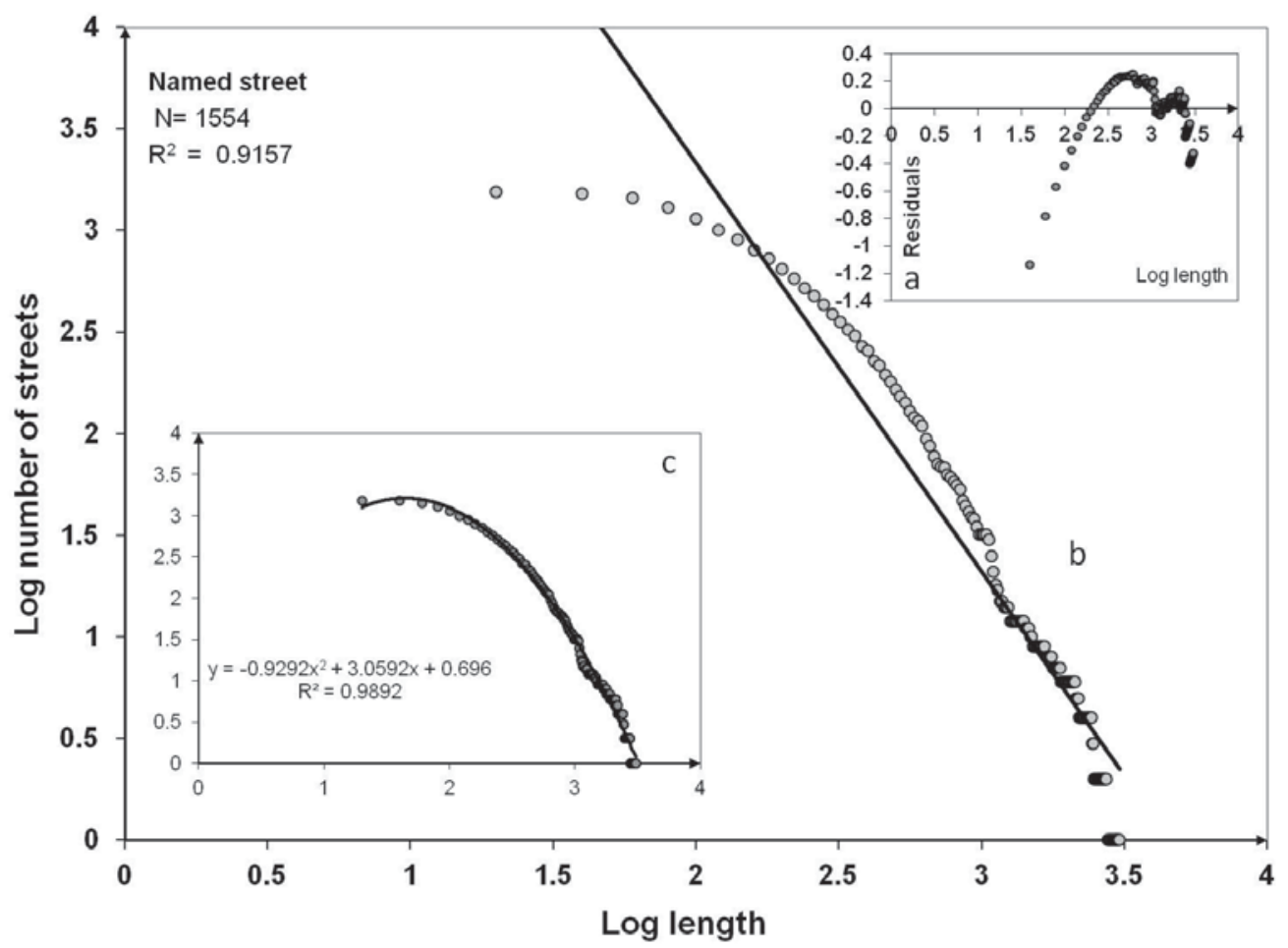

Thus, in both cases the power-laws are reasonable approximate models for the datasets, whereas the parabola-functions are somewhat better models from a purely statistical point of view. However, the difference in the $\mathrm{R}^{2}$ values between the power laws and the parabola-functions is not large enough to be, solely on the grounds of better fit, a reason for abandoning the power laws in favour of parabola-functions. 
We also tested the various power-law populations with the maximum likelihood method (e.g., [1,9]), using the program Matlab and the statistical programing language $\mathrm{R}$ [66]. Using this method, we compared the power-law fits with log-normal, exponential, and stretched exponential fits. Some of our populations fit the power-law model very well, others less well (Table 3). Briefly, if the $p$-value of the power-law model is greater than 0.1 then the power law is a plausible model for the data (e.g., street segments). However, a large $p$-value does not necessarily mean that a power law is the best model for the data. Therefore, we compared the power-law model with alternative models using a likelihood ratio test and calculating the log-likelihood ratio (LR) and corresponding $p$-value as an indication for standard deviations of that ratio.

Table 3. Tests of power-law behaviour of Dundee data sets (street segments and named streets). The symbols used are given in parenthesis as follows. Number of street segments and named street with two subpopulations (n); scaling exponent, based on the maximum likelihood estimation, $(\alpha)$ with its standard error shown; the number of observations in the power-law region (range) $\left(\mathrm{n}_{\text {tail }}\right)$ with its standard error shown; lower bound of power law $\left(\mathrm{x}_{\min }\right)$ at which the power law no longer applies, with the standard error of $\mathrm{x}_{\min }$ shown; power-law models (fits) and the corresponding $p$-values, and $p$-values for the fits and log-likelihood ratios (LR) for the alternative models.

\begin{tabular}{|c|c|c|c|c|c|c|c|}
\hline \multicolumn{8}{|c|}{ Tests of power-law behaviour in street data sets } \\
\hline \multirow{2}{*}{\multicolumn{2}{|c|}{ Dundee }} & \multicolumn{3}{|c|}{ Street segments } & \multicolumn{3}{|c|}{ Named streets } \\
\hline & & $\begin{array}{c}\text { Street } \\
\text { segments }\end{array}$ & $\begin{array}{c}\text { Coast } \\
\text { parallel }\end{array}$ & $\begin{array}{c}\text { Coast } \\
\text { perpendicular }\end{array}$ & $\begin{array}{c}\text { Named } \\
\text { street }\end{array}$ & $\begin{array}{c}\text { Coast } \\
\text { parallel }\end{array}$ & $\begin{array}{c}\text { Coast } \\
\text { perpendicular }\end{array}$ \\
\hline \multicolumn{2}{|l|}{ n } & 6004 & 2041 & 1589 & 1554 & 290 & 411 \\
\hline \multicolumn{2}{|l|}{$\alpha$} & $3.26 \pm 0.10$ & $3.07 \pm 0.16$ & $3.76 \pm 0.16$ & $3.23 \pm 0.28$ & $2.94 \pm 0.28$ & $3.321 \pm 0.25$ \\
\hline \multicolumn{2}{|l|}{$\mathbf{n}_{\text {tail }}$} & $803 \pm 175$ & $394 \pm 133$ & $305 \pm 121$ & $301 \pm 138$ & $107 \pm 26$ & $141 \pm 42$ \\
\hline \multicolumn{2}{|l|}{$\mathbf{x}_{\min }$} & $134 \pm 18$ & $135 \pm 22$ & $118 \pm 18$ & $397 \pm 92$ & $289 \pm 58$ & $234 \pm 45$ \\
\hline Power law & $p$ & 0.341 & 0.741 & 0.047 & 0.022 & 0.077 & 0.082 \\
\hline \multirow{2}{*}{ Log normal } & LR & -0.001 & -0.122 & -1.119 & -2.458 & -1.393 & -2.769 \\
\hline & $p$ & 0.49 & 0.37 & 0.271 & 0.096 & 0.172 & 0.066 \\
\hline \multirow{2}{*}{ Exponential } & LR & 104.03 & 35.28 & 9.302 & 6.861 & 1.684 & -2.259 \\
\hline & $p$ & 0.99 & 0.99 & 0.79 & 0.846 & 0.636 & 0.238 \\
\hline \multirow{2}{*}{$\begin{array}{c}\text { Stretched } \\
\text { exponential }\end{array}$} & LR & 0.412 & -0.123 & -0.961 & -2.455 & -1.473 & -3.137 \\
\hline & $p$ & 0.67 & 0.41 & 0.27 & 0.089 & 0.169 & 0.058 \\
\hline
\end{tabular}

A $p$-value tells us whether the observed sign of LR is statistically significant. If the $p$ is less than 0.1 then it is unlikely that the observed sign is a chance result of statistical fluctuations and the sign may be regarded as a reliable indicator of which of the two models gives the best fit. By contrast, if $p$ is large, the sign is not reliable and the test cannot discriminate between the two alternative models (fits).

The main reason that we use the power-law models, however, has little to do with the exactness of the fit but rather with the division of the streets and fractures into populations based on their scaling exponents. In the case of streets, the different populations have different functionality as regards traffic. In the case of fractures, the mechanics of formation differs between the populations. In the present context the main point is that the scaling exponents, as determined from the log-log plots of the 
(approximate) power laws, yield populations of different types. Furthermore, these populations, as regards their scaling exponents and length ranges, show strong linear correlations with the calculated entropies. Thus, in approximating the street and fracture populations as power laws, we have found relations that may be connected to the general physical processes, particularly energy input, that control the evolution of street and fracture populations, as is discussed further in Section 9.

\section{Discussion}

Power-law distributions may be generated using the process of continuous growth and preferential attachment $[1,2,67,68]$. In the scale-free (scale invariant) networks the nodes (or vertices) that connect through links (or edges) with other nodes are the elements that show power-law distributions $[2,3,67,68]$. That is, some nodes, referred to as hubs, have a very high number of connections, through links, to other nodes, whereas most nodes have comparatively few links to other nodes. In the street/fracture plots, however, it is not the number of lineaments that meet at particular intersections that is being plotted and provides the power-law distribution but rather the lengths of the lineaments. Since lineaments in many ways correspond better to the links than with the nodes in network analysis, this difference between the elements showing the power-law distributions in street/fracture networks and the most commonly analysed networks [2] should be kept in mind.

Both fractures and streets satisfy the conditions for continuously growing networks. For a fissure swarm, the growth of its fracture network continues so long the movements of the lithospheric plates provide the necessary energy and stress needed to keep the network growing [29]. Similarly, a street network keeps growing so long as the city that it serves keeps growing (mainly as a result of increasing population and wealth).

Many authors have explored the relationships between cities, and their spatial networks, and various mathematical and physical theories, particularly fractals [69-71], complexity theory and self-organisation [72,73], cellular automata [8], percolation theory [74] network theory [75,76], scaling relations [1-3], statistical mechanics and, in particular, entropy [77-79]. Similarly, many authors have considered the evolution of fracture systems and how they relate to stress concentrations, general theories of damage, scaling exponents and entropies [26,51,52,53,56,59,60,80-82].

Hardly any attempt, however, has been made to relate entropy to the power-law length distributions of streets and fractures in the manner done in this paper. The present calculations are based on the assumption of no constraints (in a future development of this work, the effects of various constraints will be considered). Using this assumption, however, the conclusion is that the entropies of the street/fracture populations are linearly related to their scaling exponents and length ranges (Figures 13 and 14). These results are in agreement with those obtained from street networks in some other cities [83].

\subsection{The Length-Size Distribution of the Lineaments}

The power-law size distribution of the fracture populations (Figures 2 and 12) may be partly explained in terms of Griffith's theory of fracture, which is based on the global balance of energy in a solid body (here a rock body) with existing flaws or micro-cracks (e.g, [84,85]). The theory explores (i) the energy stored as potential (including strain) energy in the solid, (ii) the energy needed to 
generate a new crack surface, and (iii) the work performed during the crack growth by the loads on the body.

The total energy $U_{t}$ of the thermodynamic system or fracture network is given by:

$$
U_{t}=\Pi+W_{s}
$$

For the fracture network, $\Pi$ is the potential energy of the that part of the plate boundary segment which hosts the network, and $W_{s}$ is the surface energy or work needed to generate two new fracture surfaces. The two possible sources of the potential energy are (i) the internal strain energy $U_{0}$ stored in the plate boundary segment prior to fracture propagation, and (ii) the work $W_{L}$ done on the boundary through the generalised plate-tectonic forces $F$ operating on the boundary while the fracture propagates.

For a fracture to propagate, the total energy $U_{t}$ [Equation (11)] must be large enough to overcome the surface energy $W_{s}$. Fracture propagation occurs when the energy release rate $G$ reaches its critical value $G_{c}$, namely when $[26,84,85]$ :

$$
G_{c}=\frac{d W_{s}}{d A}
$$

where $d A$ is the new (added) fracture surface area during fracture propagation and the energy release rate $G$ is defined as decrease in potential energy $\Pi$ [Equation (11)] as the fracture propagates, namely as:

$$
G=-\frac{d \Pi}{d A}
$$

The critical energy release rate $G_{c}$ is known as material toughness.

Equations (12) and (13) can also be expressed in terms of fracture length (half-length for a central fracture) $a$, which may be more appropriate since we deal here with fracture lengths rather than surface areas (Figures 2 and 12). Then the plane-strain energy release rate of a tension (mode I) fracture $G_{I}$ in terms of applied tensile stress $\sigma$ is given by $[26,84,85]$ :

$$
G_{I}=\frac{\sigma^{2}\left(1-v^{2}\right) \pi a}{E}
$$

where $E$ is Young's modulus and $v$ is Poisson's ratio of the host rock.

A normal fault may, depending on its geometry, be modelled either as a mode II crack or mode III crack [26]. For a normal fault modelled as a 'part-through' mode II crack, as would be appropriate for many of the shorter normal faults [27,28], the driving shear stress $\tau_{d}$ is substituted for $\sigma$ in Equation (14). A normal fault that extends from the surface of the rift zone to a magma reservoir (that is, between two free surfaces), such as applies to some of the longest normal faults studied here $[27,28]$, a mode III through-crack model is appropriate, in which case the energy release rate is $[26,84,85]$ :

$$
G_{I I I}=\frac{\tau_{d}{ }^{2}(1+v) \pi a}{E}
$$

where all the symbols are as defined above. 
Equations (12)-(15) show that for a tectonic fracture (here tension fractures and normal faults) to grow, that is, to increase its area/length, potential energy must be provided. It follows that, other things being equal, long fractures require larger energy input than shorter fractures. For a fracture in a given network to receive more energy than its neighbours, it must be favourably orientated. The NE-trending fractures in Figure (11) are perpendicular to the time-averaged local direction of the spreading vector (Figure 1b). These fractures are not only the most common but are also those that reach the greatest lengths. All the rift-zone fractures that deviate in strike much from being perpendicular the time-averaged direction of the local spreading direction receive little potential energy, soon stop growing, and remain short. Short fractures continue to form during the expansion of the network. But the gradual increase in the maximum length of the fractures as the network expands means that the fracture length range increases and, thereby, the entropy and the scaling exponent (Figure 14).

In this model of the length distribution of tectonic fractures (Figures 2 and 12), the bins in the power-low size distribution are a measure of energy levels. For a fracture to expand, that is, to increase its length so as to move from one bin to the next to the right, energy input is needed (Figure 17) to overcome the surface energy [Equations (11)-(13)]. Only exceptionally favoured fractures as regards attitude and relation to the local stress field can reach relatively great lengths in a particular fracture network. It follows that when moving to the right on the 'energy scale' (Figure 17), there will gradually fewer fractures occupying the bins, resulting in possibly a negative exponential or a power-law length distribution of fractures.

These conclusions apply to other lineaments that require energy input to grow, such as streets. Clearly streets are not formed by the same mechanism as fractures, but streets, like fractures, need energy input for their construction and growth. Mixed-mode fractures (those that are partly, say, mode I and partly mode II or mode III cracks) normally require higher energy input for their growth $[26,84,85]$. Similarly, the energy input needed for unit-length extension of a street depends on the type of street, but this energy is known and listed for constructional purposes [25,86-88]. For example, the constructional energy per kilometre for various types of roads in different European countries are summarised in [86]. This implies that, like the fractures, the streets require more and more energy to move to the right on the schematic energy scale in Figure 17. Thus, gradually fewer streets occupy bins at higher energy levels, which may result in power-laws length distributions. Since short streets continue to be constructed during the growth of the city and expansion of its street network, the gradual increase in the maximum length of street segments in the network at any time means that its length range increases and, thereby, its entropy and scaling exponent (Figure 13).

Again, like the fractures, only the most 'favourably oriented' streets have a chance of becoming long. Here 'favourably oriented' is in relation to the city shape and the street functionality within the city. Streets commonly become longer as the city to which they belong expands. For a growing street network in an expanding city, segments tend to be added to the longer streets so as to make transport to the city margins, and out of the city, possible. We may thus expect extension of some of the long street segments in a growing city, just so as to connect the existing long streets directly with the outer, developing parts of the city. By contrast, the short streets in the older, inner parts of a city cannot grow since they form a part of an already established, essentially static, part of the network. The overall shape of the city partly determines how its street network evolves and is, for example, one primary 
reason why the coast-parallel streets of Dundee are longer, that is, are more favourably oriented, on average, than its coast-perpendicular streets.

Figure 17. Schematic illustration of how the energy needed for a fracture/street to increase its length so as to move from one bin to the next bin to the right. Moving to the right along the horizontal (energy) axis on the diagram, more and more energy is needed, so that fewer and fewer fractures/streets have the energy input necessary to occupy the bins. As a results, there is a gradually decreasing height of the bins toward the right end of the energy axis.

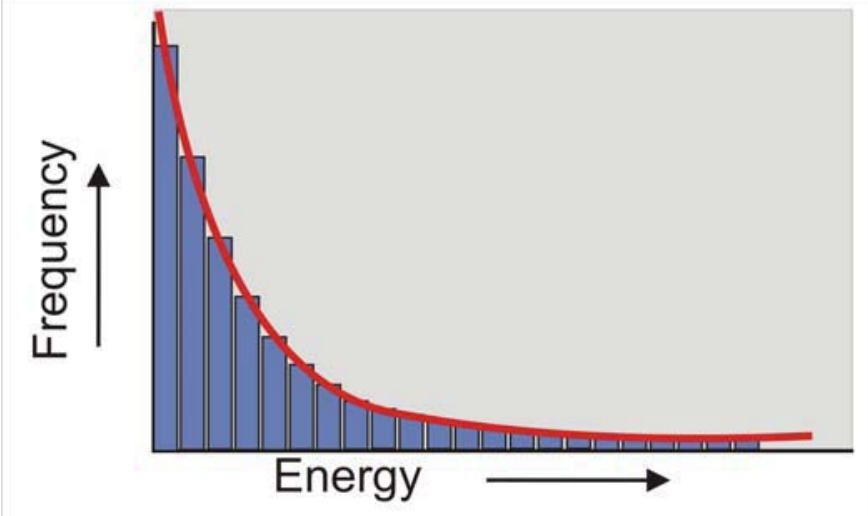

\subsection{Physical Meaning of the Entropy Results}

Let us now briefly discuss the physical meaning of the entropy values for streets and fractures in Figures 13 and 14, some of which are also presented in Tables 1 and 2. For a thermodynamic entropy, the constant $k$ in Equations (6) and (7) is Boltzmann's constant and has the value of $k_{B}=1.38065 \times$ $10^{-23} \mathrm{~J} \mathrm{~K}^{-1}$. For general probability or frequency distributions, $k$ may be regarded as an arbitrary constant with a unit value. In this paper, the entropies, as calculated from Equation (7), are dimensionless and given in units of nat. This is equivalent to Boltzmann's constant $k_{B}$ being normalised to a factor 1 . If the logarithmic base used were 2 rather than e, then the normalisation of $k_{B}$ would result in entropies in units of bits. The physical connection between the calculated entropies and the fracture/street populations, however, is through the energy input needed for their development, as discussed above. The longer the fractures/street, other things being equal, the greater must be the energy input to develop the fracture/street up to that length. The fracture/street development also produces entropy which is reflected in the entropy calculated from the power-law size distributions of the fracture/street populations.

The physical meaning of the entropy results presented here can be explored further as follows. When temperature is defined in units of energy rather than in terms of the Kelvin temperature scale then the thermodynamic entropy also becomes dimensionless $[45,48,88]$ and more easily interpreted as a measure of 'missing information' or 'degree of uncertainty' as regards a system [45,46]. In fact, Boltzmann's constant may be regarded as a conversion factor between the units of energy and the units of temperature [45], as is needed when temperature and energy are measured using different scales. Thus, if the entropies in this paper, such as in Tables 1 and 2, were multiplied by the value of $k_{B}$ their units would be those of standard thermodynamic entropy. 
'Missing information' is another name for 'information entropy', which is widely regarded as providing one of the foundations of modern statistical mechanics [48,49,89-96]. In particular, for equilibrium systems there is a general correspondence between information and thermodynamic entropies [94]. The fracture/street populations in the present study may be regarded as systems in close-to-equilibrium except during episodes of rapid city growth, for the streets, and volcanotectonic rifting episodes, for the fractures. Experimental demonstrations showing how information may be converted into energy [97] provide additional support for the connection between information theory and statistical mechanics.

\section{Conclusions}

- The paper presents the results of the trend and length measurements of crustal fractures in the active rift zone of Iceland and streets in the city of Dundee in East Scotland. The results of the measurements of a total of 221 fractures are given, all of which belong to two fracture networks (or swarms) in young lava flows in Southwest Iceland. The fractures show roughly normal distributions as regards trend (azimuth), with the mean trend being northeast. The fractures range in length from $40 \mathrm{~m}$ to $7700 \mathrm{~m}$, with an average of $617 \mathrm{~m}$, and show a power-law length distribution.

- Measurements of 1554 named streets and 6004 street segments in the city of Dundee, located at the coast of the Firth of Tay, show two main trends: one parallel to the coast (coast-parallel) and the other perpendicular to the coast (coast-perpendicular). Each of these main trends has a close-to normal distribution, the mean trends for the coast-parallel streets being 80-90 degrees and for the coast-perpendicular trends 160-170 degrees. The main trends are thus orthogonal.

- The named streets range in length from $15 \mathrm{~m}$ to $3023 \mathrm{~m}$, whereas the street segments range from $3 \mathrm{~m}$ to $2249 \mathrm{~m}$. Both named streets and segments follow power-law length distributions. Using bi-logarithmic (log-log) plots, the streets can be divided into several populations based on the differences in slopes of the straight lines on the plots, that is, on the population scaling exponents.

- It is proposed that the fracture networks in Iceland and the street networks in Dundee are both partly determined by external constraints. In Iceland, these constraints are primarily related to the shapes of the swarms that contain the fractures which are elongated (elliptical) with major axes roughly parallel with the axis of the rift zone. In Dundee, the overall shape of the city is semi-elliptical where the main external constraint is the coastline. It is shown that the coast-parallel streets are, on average, longer than the coast-perpendicular streets and that this is largely the effect of the coast as a landscape constraint.

- Analysis of the street networks using equations from statistical mechanics for the entropy of a general probability (frequency) distribution indicates that the coast-parallel named streets have the highest entropy of all the main trends. Also, when taking all the street populations into account, there is a clear relation between entropy and scaling exponents of the populations of the streets. More specifically, the scaling exponents of a given population of streets (named and segments) is linearly proportional to the entropy of that population; that is, the larger the scaling exponent, the larger is the entropy. Very similar linear relationships are obtained between the scaling exponents 
and the entropies of the fracture populations. Furthermore, the entropy of a street/fracture population varies linearly as the range in street/fracture length of that population.

- It is proposed that the power-law size distributions of the streets and fracture lengths may be related to the energy input needed to extend the streets/fractures. The longer the fractures/street, other things being equal, the greater must be the energy input to develop the fracture/street up to that length. The fracture/street development also produces entropy which is reflected in the entropy calculated from the power-law size distributions of the fracture/street populations. Only exceptionally 'favoured' fractures/streets can reach relatively great lengths in a particular fracture/street network. It follows that when moving to the right on the 'energy scale' (Figure 17), there will gradually fewer fractures/streets occupying the bins, which may result in a power-law length distribution of fractures and streets.

\section{Acknowledgements}

We thank the three anonymous Entropy reviewers for very helpful comments on an earlier version of this paper.

\section{References}

1. Newman, M.E.J. Power laws, Pareto distributions and Zipf's law. Contemp. Phys. 2005, 46, 323-351.

2. Newman, M.E.J. Networks: An Introduction; Oxford University Press: Oxford, UK, 2010.

3. Barabasi, A.L.; Bonabeau, E. Scale-free networks. Sci. Am. 2003, 288, 50-59.

4. Zipf, G.K. Human Behaviour and the Principle of Least Effort: An Introduction to Human Ecology; Addison-Wesley: Cambridge, UK, 1949.

5. Stewart, J.Q. The development of social physics. Am. J. Phys. 1950, 18, 290-53.

6. Turcotte, D.L. Fractals and Chaos in Geology and Geophysics, 2nd ed.; Cambridge University Press: Cambridge, UK, 1997.

7. Sornette, D. Critical Phenomena in Natural Sciences; Springer: New York, NY, USA, 2006.

8. Batty, M. Cities and Complexity: Understanding Cities with Cellular Automata, Agent-Based Models, and Fractals; MIT Press: Cambridge, MA, USA, 2005.

9. Clauset, A; Chalizi, R.C.; Newman, M.E.J. Power-law distributions in empirical data. Soc. Ind. Appl. Math. 2009, 51, 661-703.

10. Schroeder, M.R. Fractals, Chaos, Power laws; Dover: New York, NY, USA, 2009.

11. Ollier, C. Tectonics and Landforms; Longman: New York, NY, USA, 1981.

12. Scheidegger, A.E. Theoretical Geomorphology, 2nd ed.; Springer: New York, NY, USA, 1970.

13. Burbank, D.W.; Anderson, R.S. Tectonic Geomorphology; Blackwell: Oxford, UK, 2000.

14. Hillier, B. The hidden geometry of deformed grids: Or, why space syntax works, when it looks as though it shouldn't. Environ. Plann. Plann. Des. 1999, 26, 169-171.

15. Hillier, B. A theory of the city as object. In Proceedings of the Third Space Syntax International Symposium, Georgia Institute of Technology, Atlanta, GA, USA, 7-11 May 2001; Peponis, J., Wineman, J., Bafna, S., Eds.; pp. 1-28.

16. Marshall, S. Streets and Patterns; Taylor and Francis: London, UK, 2005. 
17. Rui, C; Penn, A. Scaling and universality in the micro-structure of urban space. Physica A 2004, $332,539-547$.

18. Jiang, B; Claramunt, C. Topological analysis of urban street networks. Environ. Plann. Plann. Des. 2004, 31, 151-162

19. Watson, N. Dundee: A Short History; Black and White: London, UK, 2006.

20. Ferguson, G.N. Dundee: A History and Celebration of the City; Francis Firth: Dinton, UK, 2005.

21. Williams, G.P. Chaos Theory Tamed; Taylor and Francis: London, UK, 1997.

22. Matlab, version R2011b; The MathWorks, Inc.: Cambridge, UK, 2011. Available online: http://www.mathworks.com/ (accessed on 14 August 2011).

23. Statistica, version 10; StatSoft Ltd.: Tulsa, OK, USA, 2011. Available online: http://www.statsoft.co.uk/ (accessed on 28 October 2011).

24. Pareto, V. Cours d'Economie Politique; Droz: Geneva, Switzerland, 1896 (reprinted as a volume of complete publications 1965).

25. Commission. Integration of the Measurement of Energy Usage into Road Design; Brussel, Commission of the European Communities Directorate-General for Energy and Transport. Final Report, 2006. Project number 4.1031/Z/02-09/2002.

26. Gudmundsson, A. Rock Fractures in Geological Processes; Cambridge University Press: Cambridge, UK, 2011.

27. Gudmundsson, A. Tectonics of the Thingvellir fissure swarm, SW Iceland. J. Struct. Geol. 1987, 9, 61-69.

28. Gudmundsson, A. Geometry, formation and development of tectonic fractures on the Reykjanes Peninsula, Southwest Iceland. Tectonophysics 1987, 139, 295-308.

29. Gudmundsson, A. Dynamics of volcanic systems in Iceland: Example of tectonism and volcanism at juxtaposed hotspot and mid-ocean ridge systems. Annu. Rev. Earth Planet. Sci. 2000, 28, 107-140.

30. Sigmundsson, F. Iceland Geodynamics; Springer: Berlin, Germany, 2006.

31. Swan, A.R.H.; Sandilands, M. Introduction to Geological Data Analysis; Blackwell: Oxford, UK, 1995.

32. Smith, M.J.; Goodchild, M.F.; Longley, P. Geospatial Analysis: A Comprehensive Guide, 3rd ed.; Troubador Publishing Ltd: London, UK, 2009.

33. GEOrient, version 9.5.0; Torus Knot Software Ltd.: Tallai, Australia, 2011. Available online: http://www.geoorient.com/ (accessed on 29 January 2011).

34. Trewin, N.H.; Editor. The Geology of Scotland, 4th ed.; The Geological Society of London: London, UK, 2002.

35. Han, D.D.; Qian, J.H.; Ma, Y.G. Emergence of double scaling law in complex systems. Europhys. Lett. 2011, 94, 28006.

36. Hatton, C.G.; Main, I.G.; Meredith, P.G. Non-universal scaling of fracture length and opening displacement. Nature 1994, 367, 160-162.

37. Larsen B.; Grunnaleite, L.; Gudmundsson, A. How fracture systems affect permeability development in shallow-water carbonate rocks: An example from the Gargano Peninsula, Italy. J. Struct. Geol. 2010, 32, 1212-1230. 
38. Gudmundsson, A. Formation and growth of normal faults at the divergent plate boundary in Iceland. Terra Nova 1992, 4, 464-471.

39. Headicar, P. Transport Policy and Planning in Great Britain; Taylor and Francis: London, UK, 2009.

40. Road Atlas of Britain. Big Road Atlas, Britain. Automobile Association Developments Limited, 17th ed.; Basingstoke: Hampshire, UK, 2008.

41. Road Atlas of Britain. Large-Scale Road Atlas, Britain. Automobile Association Developments Limited, 7th ed.; Basingstoke: Hampshire, UK, 2010.

42. Wilson, A.G. Entropy in Urban and Regional Modelling; Pion: London, UK, 1970.

43. Mandl, F. Statistical Physics, 2nd ed.; Wiley: New York, NY, USA, 1988.

44. Dill, K.A.; Bromberg, S. Molecular Driving Forces: Statistical Thermodynamics in Chemistry and Biology; Taylor and Francis: London, UK, 2003.

45. Sethna, J.P. Statistical Mechanics: Entropy, Order, Parameters, and Complexity; Oxford University Press: Oxford, UK, 2006.

46. Blundell, S.J.; Blundell, K.M. Concepts in Thermal Physics; Oxford University Press: Oxford, UK, 2006.

47. Kardar, M. Statistical Physics of Particles; Cambridge University Press: Cambridge, UK, 2007.

48. Ben-Naim, A. A Farewell to Entropy: Statistical Thermodynamics Based on Information Theory; World scientific Publishing Corporation: Singapore, 2008.

49. Volkenstein, M.V. Entropy and Information; Birkhauser: Berlin, Germany, 2009.

50. Cover, T.M.; Thomas, J.A. Elements of Information Theory; Wiley: Hoboken, NJ, USA, 2006.

51. Lu, C.; Mai, Y.W.; Xie, H. A sudden drop of scaling exponent: A likely precursor of catastrophic failure in disordered media. Phil. Mag. Lett. 2005, 85, 33-40.

52. Xie, H. Fractals in Rock Mechanics; Rotterdam: Balkema, The Netherlands, 1993.

53. Adler, P.M.; Thovert, J.F. Fractures and Fracture Networks; Kluwer: London, UK, 1999.

54. Shimada, M. Mechanical Behavior of Rocks under High Pressure Conditions; Balkema: Rotterdam, The Netherlands, 2000.

55. Zang, X.; Sanderson, D.J. Numerical Modelling and Analysis of Fluid Flow and Deformation of Fractured Rock Masses; Pergamon: London, UK, 2002.

56. Mishnaevsky, L. Damage and Fracture in Heterogeneous Materials; Balkema: Rotterdam, The Netherlands, 1998.

57. Mishnaevsky, L. Computational Mesomechanics of Composites; Wiley: New York, USA, 2007.

58. Stauffer, D.; Aharony, A. Introduction to Percolation Theory, 2nd ed.; Taylor and Francis: London, UK, 1994.

59. Bao, T.F.; Peng, Y.; Cong, P.J.; Wang, J.L. Analysis of crack propagation in concrete structures with structural information entropy. Science China Technological Sciences 2010, 53, 1943-1948.

60. Naderi, M.; Amiri, M.; Khonsari, M.M. On the thermodynamic entropy of fatigue fracture. Proc. Roy. Soc. Lond. 2010, A466, 423-438.

61. Qi, G.; Wayne, S.F.; Fan, M. Measurements of a multicomponent variate in assessing evolving damage states in a polymeric material. IEEE T. Instrum. Meas. 2011, 60, 206-213.

62. Huges, I.G.; Hase, T.P.A. Measurements and Their Uncertainties; Oxford University Press: Oxford, UK, 2010. 
63. Berendsen, H.J.C. Data and Error Analysis; Cambridge University Press: Cambridge, UK, 2011.

64. Taylor, J.R. An Introduction to Error Analysis: the Study of Uncertainties in Physical Measurements, 2nd ed.; University Science Books: Herndon, VA, USA, 1997.

65. Drog, M. Dealing with Uncertainties: A Guide to Error Analysis; Springer Verlag: Berlin, Germany, 2009.

66. The statistical programing language R, version 9.4.5. Available online: http://www.r-project.org (accessed on 9 May 2010).

67. Albert, R.; Barabasi, A.L. Statistical mechanics of complex networks. Rev. Mod. Phys. 2002, 74, 47-97.

68. Barabasi, A.L.; Albert, R. Emergence of scaling in random networks. Science 1999, 286, 509-512.

69. Batty, M.; Longley, P. Fractal Cities; Academic Press: New York, NY, USA, 2004.

70. Carvalho, R.; Penn, A. Scaling and universality in the micro-structure of urban space. Physica $A$ 2004, 32, 539-547.

71. Thomas, I.; Frankhauser, P.; Biernacki, C. The fractal morphology of the built-up landscape. Landsc. Urban Plann. 2008, 84, 99-115.

72. Albeverio, S.; Andrey, D.; Giordano, P.; Vancheri, A, Eds. The Dynamics of Complex Urban Systems: An Interdisciplinary Approach; Physica-Verlag: Heidelberg, Germany, 2007.

73. Jiang, B. A topological pattern of urban street networks; universality and peculiarity. Physica $A$ 2007, 384, 647-655.

74. Makse, H.A.; Havlin, S.; Stanley, H.E. Modelling urban growth patterns. Nature 1995, 377 , 608-612.

75. Xie, F; Levinson, D. Measuring the structure of road network. Geogr. Anal. 2007, 39, 336-356.

76. Porta, S; Crucitti, P; Latora, V. The network analysis of urban streets: A dual approach. Physica A 2006, 369, 853-866.

77. Wilson, A.G. A statistical theory of spatial distribution models. Transport. Res. 1967, 1, 253-269.

78. Batty, M. Entropy and spatial geometry. Area 1972, 4, 230-236.

79. Batty, M. Spatial entropy. Geogr. Anal. 1974, 6, 1-31.

80. Naderi, M.; Kahirdeh, A.; Khonsari, M.M. Dissipated thermal energy and damage evolution of glass/epoxy using infrared therography and acoustic emission. Compos. B Eng. 2012, 43, 1613-1620.

81. Mishnaevsky Jr, L.L.; Schmauder, S. Damage evolution and localization in heterogeneous materials under dynamical loading: Stochastic modelling. Comput. Mech. 1997, 20, 89-94.

82. Mishnaevsky, L.L., Jr. Methods of the theory of complex systems in modelling of fracture: A brief review. Eng. Fract. Mech. 1997, 56, 47-56.

83. Mohajeri, N. Effects of landscape constraints on street patterns in cities: examples from Khorramabad, Iran. Appl. Geogr. 2012, 34, 10-20.

84. Broberg, K.B. Cracks and Fracture; Academic Press: London, UK, 1999.

85. Anderson, T.L. Fracture Mechanics, 3rd ed.; Taylor and Francis: London, UK, 2005. 
86. Jackson, P. Sustainable roads-Energy efficiency in road design, construction and operation. Information Systems Panel Briefing Sheet 2007. Available online: http://www.ice.org.uk/ Information-resources/Document-Library/Sustainable-roads---energy-efficiency-in-road-desi (accessed on 11 April 2012).

87. Zapata, P.; Gambatese, J.A. Energy consumption of asphalt and reinforced concrete pavement materials and construction. J. Infrastruct. Syst. 2005, 11, 9-20.

88. Leff, H.S. What if entropy were dimensionless? Am. J. Phys. 1999, 67, 1114-1122.

89. Jaynes, E.T. Information theory and statistical mechanics, II. Phys. Rev. 1957, 108, 171-190.

90. Jaynes, E.T. Information theory and statistical mechanics. Phys. Rev. 1957, 106, 620-630.

91. Jaynes, E.T. Probability Theory: The Logic of Science. Principles and Elementary Applications; Cambridge University Press: Cambridge, UK, 2003; Volume 1.

92. Bashkirov, A.G; Vityazev, A.V. Information entropy and power-law distributions for chaotic systems. Physica A 2000, 277, 136-145.

93. Baierlein, R. Atoms and Information Theory: An Introduction to Statistical Mechanics; W.H. Freeman: San Francisco, CA, USA, 1971.

94. Laurendeau, N.M. Statistical Thermodynamics: Fundamentals and Applications; Cambridge University Press: Cambridge, UK, 2005.

95. Graham, D.J. Chemical Thermodynamics and Information Theory with Applications; CRC Press: New York, NY, USA, 2011.

96. Robertson, H.S. Statistical Thermophysics; Prentice-Hall: Englewood Cliffs, NJ, USA, 1998.

97. Toyabe, S.; Sagawa, T.; Ueda, M.; Muneyuki, E., Sano, M. Experimental demonstration of information-to-energy conversion and validation of the generalized Jarzynski equality. Nat. Phys. 2010, 6, 988-992.

(C) 2012 by the authors; licensee MDPI, Basel, Switzerland. This article is an open access article distributed under the terms and conditions of the Creative Commons Attribution license (http://creativecommons.org/licenses/by/3.0/). 